\title{
COLHEITA FLORESTAL: MENSURAÇÃO E ANÁLISE DOS EFEITOS DAS VARIÁVEIS CONTROLÁVEIS E NÃO CONTROLÁVEIS NO CUSTO DAS ATIVIDADES DE CORTE E DESCASQUE MECANIZADO
}

\author{
MARCOS ANTONIO DE SOUZA \\ Doutor em Controladoria e Contabilidade pela \\ Universidade de São Paulo \\ Professor Titular da Universidade do Vale do Rio dos Sinos \\ E-mail: marcosas@unisino.br
}

CHARLINE BARBOSA PIRES

Graduada em Ciências Contábeis pela

Universidade do Vale do Rio dos Sinos

E-mail: charlinepires@uol.com.br

FABIANA COSTA SILVEIRA

Mestre em Ciências Contábeis pela Universidade do Vale do Rio dos Sinos

E-mail: fsilveira@sesirs.org.br

\section{Resumo}

O estudo trata da classificação, mensuração e análise dos custos envolvidos na prestação de serviços de colheita florestal, mais especificamente das atividades de corte e descasque de madeira de eucalipto para fabricação de celulose. Analisa as atividades mecanizadas de corte e descasque, descrevendo os principais elementos de custos envolvidos na sua realização e a forma como estes se comportam em relação ao objeto de custeio. Trata-se de um estudo de caso único, desenvolvido durante o primeiro semestre de 2006, que utilizou como fontes de evidências a observação direta, entrevistas, documentações e registros em arquivos. Com base nos dados que disponibiliza, conclui-se que o modelo apresentado pode auxiliar na gestão econômica das empresas, oferecendo subsídios para o processo decisório sobre custos, controle de produtividade e negociação do preço de venda.

Palavras-chave: contabilidade florestal; gestão de custos; atividade florestal; mecanização florestal.

\begin{abstract}
This study deals with the classification, measurement and analysis of the costs evolved in forestry. Specifically it cares for the activities of cutting and shelling of eucalyptus wood for pulp fabrication. It analyses cutting and shelling mechanized activities, describing the main elements of costs evolved in its realization and the way these elements behave in relation to the costing object. It is a single case study, developed during year 2006 first semester, and has utilized as source of evidence direct observation, interviews, documentation and file records. Based on the available data, the conclusion is that the presented model can help on companies' economic management, offering subsides for the decision process about costs, productivity control and selling price negotiation.
\end{abstract}

Key words: forestry accounting, costs management, forestry activity, forestry mechanization. 


\section{INTRODUÇÃO}

As mudanças ocorridas no mercado nacional e internacional alteraram de forma significativa a estrutura produtiva das empresas que atuam no setor florestal, tornando necessária a implementação de medidas capazes de viabilizar a adequação das mesmas aos padrões internacionais de produtividade, qualidade e custos. Uma destas medidas é a transferência das atividades de colheita florestal para empresas especializadas (terceirização da colheita florestal), dado que parcela significativa do custo total da madeira utilizada nas fábricas está relacionada ao ciclo de atividades que compreende desde o corte das florestas até o seu transporte ao consumidor final.

Enquanto algumas empresas optam por terceirizar apenas parte das atividades realizadas, outras transferem para terceiros todo o processo. Estudo realizado por Leite, Souza e Machado (2002) em 15 grandes empresas brasileiras de reflorestamento identificou que a adoção da estratégia de terceirização na colheita florestal situava-se conforme apresentado na Tabela 1.

Tabela 1: Terceirização na Colheita Florestal

\begin{tabular}{|l|c|}
\multicolumn{1}{|c|}{ Atividades } & \% Terceirizado \\
\hline Extração & 63,30 \\
\hline Carregamento & 69,30 \\
\hline Transporte & 100,0 \\
\hline Descarregamento & 56,30 \\
\hline Média & $\mathbf{7 1 , 0}$
\end{tabular}

Fonte: LEITE et al.(2002)

Verifica-se que é expressivo o uso de serviços terceirizados pelas empresas do setor (71\%). Leite, Souza e Machado (2002) destacam que a terceirização nessa área é crescente e representa uma oportunidade para aquelas organizações capazes de atender os níveis de exigência das empresas clientes. Nesse contexto, as empresas especializadas em colheita florestal têm sido desafiadas a oferecer seus serviços a um custo aceitável, a cumprir da quota de produção dentro do prazo contratado, garantir qualidade e adequação às normas trabalhistas e ambientais etc. Contudo, atender o crescente nível de exigência das empresas contratantes, oferecendo serviços a um preço competitivo e, ao mesmo tempo, assegurar o retorno do investimento realizado, não é o único desafio das empresas que atuam no setor de colheita florestal, pois as características do processo produtivo, que evoluiu da colheita manual e semimecanizada para a mecanizada, modificaram significativamente as suas estruturas de custos e, por conseqüência, a forma de administrá-los. Assim, desenvolver mecanismos para a mensuração dos custos com a realização dessas atividades, bem como o controle dos elementos que exercem maior influência no custo final do serviço prestado, pode auxiliar o gestor na busca pela otimização do resultado organizacional.

Dessa forma, o objetivo do estudo é a mensuração e a análise dos custos envolvidos na prestação de serviços mecanizados de colheita florestal, mais especificamente da etapa de corte e descasque. É apresentado um modelo que possibilita a identificação do custo final do serviço prestado, viabilizando o gerenciamento dos fatores característicos deste tipo de atividade no resultado da empresa. Para tanto, cumprem-se cinco etapas: (1) conhecer as atividades que compõem a cadeia de produção do sistema de colheita florestal; (2) entender as atividades mecanizadas de corte e descasque; (3) identificar, mensurar e analisar os custos envolvidos; (4) mensurar o resultado das operações; (5) analisar o preço de venda, margem de contribuição e ponto de equilíbrio. Entende-se que 
a contribuição do estudo está em evidenciar uma aplicação prática do custeio da colheita florestal e oportunizar a discussão da mensuração de custos e resultados em um segmento não explorado com freqüência pela literatura pertinente.

\section{A ATIVIDADE FLORESTAL}

A cadeia produtiva do setor florestal é composta por três segmentos básicos: (1) madeira para energia (lenha e carvão); (2) madeira industrial (celulose e papel; painéis de madeira reconstituída); (3) processamento mecânico (serrados e laminados), conforme demonstrado na Figura 1. Acrescenta-se que este trabalho está direcionado a analisar a colheita de florestas que abastecem as indústrias do segmento de madeira industrial, subsegmento celulose e papel.

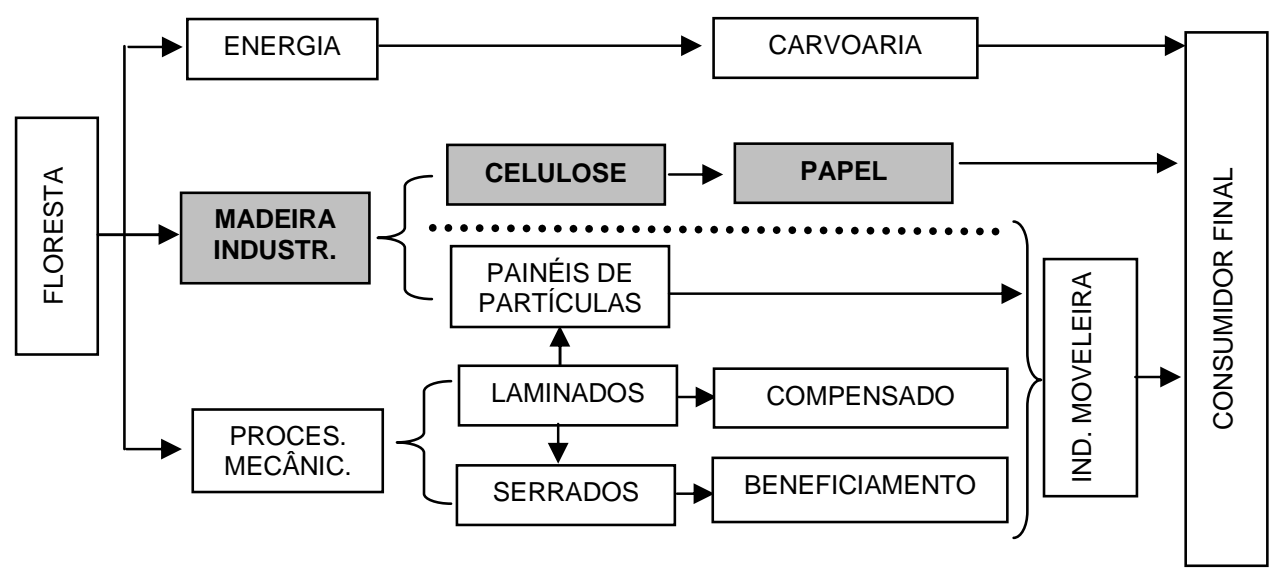

Figura 1: Cadeia Produtiva do Setor Florestal

Fonte: Adaptada de POLZL et. al. (2003)

Segundo Carvalho, Soares e Valverde (2005), a indústria de celulose e papel é a mais bem sucedida do setor florestal. Dados da Bracelpa (2006a) indicam que em 2005 o setor participou com 1,4\% do Produto Interno Bruto (PIB) brasileiro e compreende a atuação de 220 empresas, sendo 35 delas exportadoras habituais. A Tabela 2 relaciona os principais produtores de celulose e respectivas participações no mercado nacional.

Tabela 2: Principais Produtores de Celulose do Brasil em 2004

\begin{tabular}{|l|c|}
\multicolumn{1}{|c|}{ Empresa } & $\begin{array}{c}\text { Participaçã } \\
\text { o \% }\end{array}$ \\
\hline Aracruz Celulose S.A. & 26,0 \\
\hline Votorantin Celulose e Papel S.A. & 14,0 \\
\hline Klabin S.A. & 11,9 \\
\hline Suzano Bahia Sul & 11,5 \\
\hline Celulose Nipo-Brasileira S.A. - Cenibra & 9,5 \\
\hline Ripasa S.A. Celulose e Papel & 4,9 \\
\hline International Paper do Brasil Ltda. & 4,7 \\
\hline Jarí Celulose S.A. & 3,7 \\
\hline Rigesa Celulose, Papel e Embalagens. Ltda. & 2,3 \\
\hline Norske Skog Pisa Ltda. & 1,8 \\
\hline Demais & 9,9
\end{tabular}

Fonte: Adaptada de BRACELPA(2006b) 
De acordo como Parise (2005) o processo produtivo das empresas que realizam serviços de colheita florestal no Brasil tem sofrido alterações significativas nos últimos anos, evoluindo da colheita manual e semimecanizada para a mecanizada. A evolução da colheita florestal no país pode ser dividida em quatro fases distintas, conforme apresentado na Figura 2.

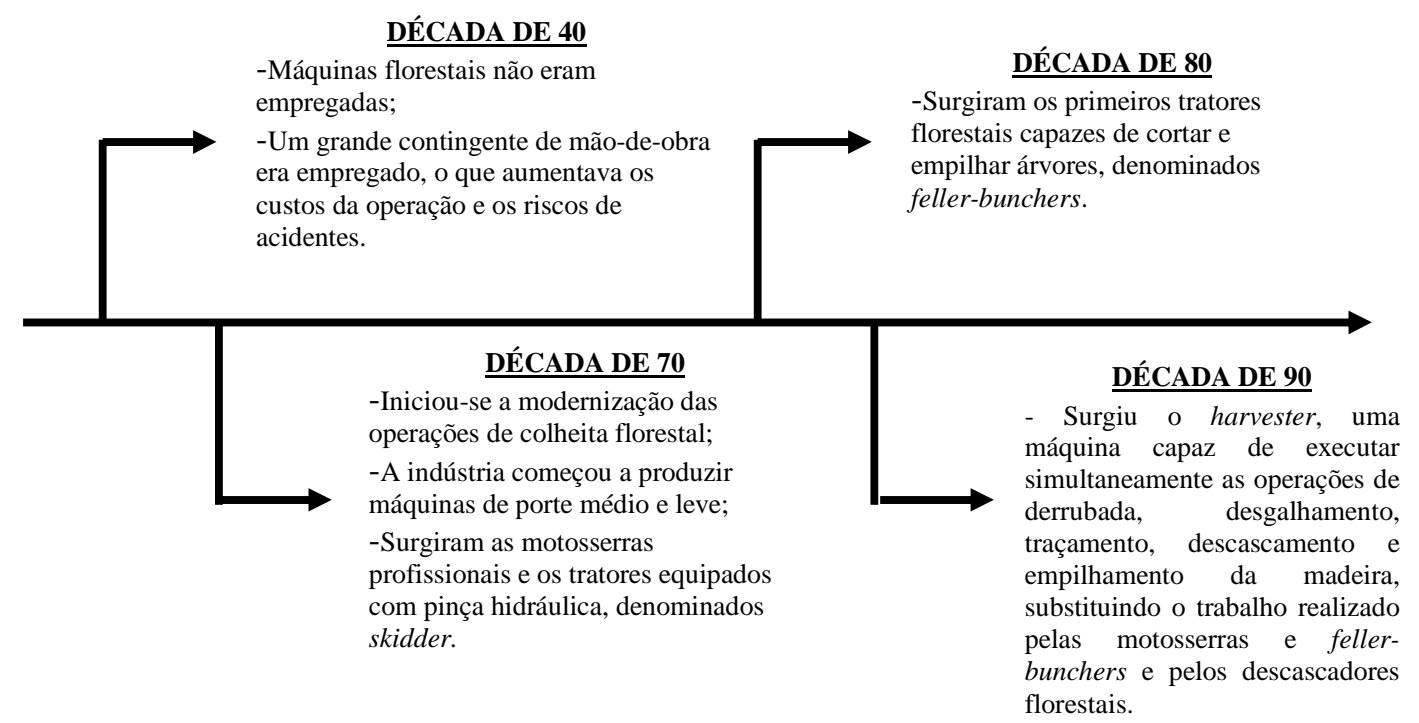

Figura 2: A Evolução dos Sistemas de Colheita Florestal no Brasil Fonte: Adaptada de MACHADO (2002)

É claro que nem todas as empresas encontram-se atualmente na fase de mecanização completa, algumas delas continuam adotando os métodos de produção manuais e semimecanizados utilizados nas décadas anteriores. De acordo com Machado (2002), o mercado atual de prestação de serviços de colheita florestal é explorado por três grandes grupos de empresas: (a) grandes empresas: dispõem de máquinas leves, médias e pesadas, altamente sofisticadas; (b) empresas de médio porte: utilizam máquinas e equipamentos pouco sofisticados e mão-de-obra especializada; (c) pequenas empresas: continuam a utilizar métodos de colheita rudimentares e mão-de-obra pouco qualificada.

Este trabalho está focado nas empresas que prestam serviços de colheita florestal às empresas produtoras de celulose, detentoras das florestas, utilizando máquinas altamente sofisticadas na realização de suas atividades, ou seja, que realizam corte e descasque mecanizado.

Segundo Parise (2005), a intensificação do processo de mecanização da colheita florestal resultou em vários benefícios para as empresas que atuam no setor, dentre os quais se pode citar a redução da necessidade de mão-de-obra; maior produtividade; melhor qualidade; possibilidade de operação durante 24 horas mesmo em condições climáticas adversas; maior eficiência; redução dos impactos ambientais etc. Diante dos benefícios listados por Parise, depreende-se que a mecanização da colheita florestal permitiu que as empresas prestadoras de serviços passassem a oferecer um produto de maior qualidade e com menores custos. Todavia, é relevante mencionar que a transição do processo manual ou semimecanizado para o mecanizado demandou, por parte das empresas terceirizadas, investimentos em equipamentos e estruturas de apoio, bem como 
em treinamento de funcionários. Tais ações alteraram significativamente a estrutura de custos, já que a mão-de-obra barata e pouco qualificada foi substituída por máquinas sofisticadas de elevado valor e passou a demandar a utilização de mão-de-obra especializada.

Diante dessa nova realidade é importante, como forma de assegurar a continuidade dos negócios, a compreensão da nova estrutura de custos e o seu impacto na competitividade da organização.

\section{A COLHEITA FLORESTAL}

Malinovski e Malinovski (1998) definem a colheita florestal como uma cadeia produtiva formada por etapas denominadas atividades parciais, as quais englobam desde a derrubada das árvores até a colocação da madeira no pátio da indústria consumidora. De modo geral, o sistema de colheita de madeira abrange as seguintes atividades: (1) corte: compreende as operações de derrubada, desgalhamento, traçamento das árvores em toras ou toretes e empilhamento da madeira; (2) descasque: objetiva separar a casca do tronco, em razão das necessidades do produto final e, por isso, é uma atividade opcional; (3) extração: fase relacionada ao transporte da madeira do local de corte até a beira da estrada, carreador ou pátio intermediário, de onde é transferida para os veículos que fazem o transporte final até as fontes consumidoras; (4) carregamento: representa a colocação da madeira extraída nos veículos que a transportam até o local de utilização final ou pátios especiais; (5) transporte às fontes consumidoras: consiste no transporte da madeira coletada da floresta até o centro de consumo; (7) descarregamento: última etapa da cadeia de produção; corresponde à retirada da madeira do veículo de transporte e sua colocação no pátio da empresa consumidora (Figura 3).

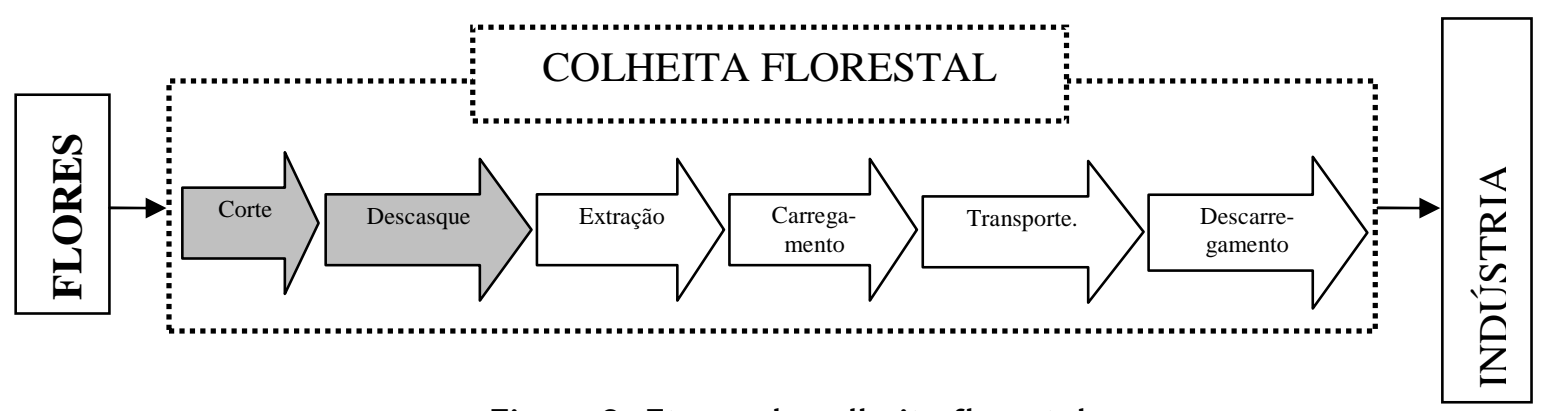

Figura 3: Etapas da colheita florestal

Fonte: Elaborado a partir de Malisnoviski e Malisnoviski (1998)

No caso da empresa em estudo, as atividades são desenvolvidas sob as seguintes condições operacionais básicas: (1) corte e descasque mecanizado: um único equipamento, denominado harvester, executa simultaneamente as operações de derrubada, desgalhamento, traçamento, descascamento e empilhamento da madeira (MACHADO, 2002).

A escolha desta atividade como foco da análise justifica-se pelo fato de que é ela quem demanda o maior volume de investimentos, quando comparada com as demais etapas do serviço de colheita florestal, sendo responsável, também, pela maior parcela de faturamento naquelas empresas que realizam todas as atividades.

Adicionalmente, entende-se que o modelo apresentado pode ser utilizado, 
mediante adaptações, na mensuração e análise dos custos incorridos nas etapas de extração, carregamento e descarregamento.

\section{PROCEDIMENTOS METODOLÓGICOS}

Nesta pesquisa adota-se a metodologia de estudo de caso único, definido por Yin (2005, p. 32) como sendo "uma investigação empírica que investiga um fenômeno contemporâneo dentro de seu contexto da vida real". Seguindo-se a recomendação de Yin (2005), utilizou-se um protocolo de estudo de caso que, de acordo com o autor, contribui para aumentar a confiabilidade da pesquisa realizada e orientar o pesquisador no processo de coleta de dados. É composto, basicamente, pelas seguintes seções: (a) visão geral do projeto de estudo de caso; (2) os procedimentos de campo; (3) as questões de estudo de caso e (4) um guia para relatório de estudo de caso.

0 estudo foi realizado durante o primeiro semestre de 2006 na sede de uma empresa que atua no setor de colheita florestal e realiza serviços de corte, descasque, extração, carregamento e transporte de madeira de eucalipto, cujo principal cliente é uma fábrica de papel e celulose. Ambas as empresas estão localizadas no estado do Rio Grande do Sul. A contratada (prestadora de serviços) foi constituída há 16 anos, conta atualmente com 80 funcionários e realiza a atividades de corte e descasque mecanizado desde 2003, sendo uma das pioneiras na utilização de equipamentos harvester no estado. A contratante, também uma empresa brasileira, é líder mundial na produção de celulose branqueada de eucalipto, respondendo por cerca de $30 \%$ da oferta global do produto.

Para coleta de dados utilizou-se: (1) observação direta; (2) entrevista; (3) documentação e (4) registros em arquivos. Para que fosse possível mapear os processos e identificar as características das atividades executadas, fez-se uma visita ao horto florestal onde a empresa realiza os serviços. Na segunda etapa da pesquisa, com base em Roesch (2005), foram feitas entrevistas semi-estruturadas, utilizando-se de questões abertas. Os participantes das entrevistas foram (Quadro 1):

\begin{tabular}{|l|l|}
\multicolumn{1}{|c|}{ Contratante } & \multicolumn{1}{c|}{ Contratada } \\
\hline Gerente Florestal & Diretor Geral \\
\hline Gerente de Custos & Supervisor de Colheita \\
\hline Analista de Custos & Encarregado de Corte \\
\hline
\end{tabular}

Quadro 1: Participantes das entrevistas

Os tópicos principais abordados durante as entrevistas foram os seguintes: (1) estrutura organizacional, departamentos existentes e suas funções; (2) base de receita de cada serviço prestado; (3) custos incorridos na realização de cada atividade; (4) níveis de consumo de matéria-prima e de utilização de mão-de-obra direta; $(5)$ características dos equipamentos utilizados; (6) peculiaridades envolvidas na realização de cada atividade; (7) possíveis impactos destas peculiaridades nos custos dos serviços prestados. Por fim, com o objetivo de complementar as informações coletadas através das observações e entrevistas, realizou-se uma pesquisa documental. Foram analisados diversos relatórios internos da empresa, obtendo-se dados históricos de produções e consumos médios. Os dados utilizados no estudo referem-se à produção realizada no mês de abril de 2006. Os conceitos utilizados nos procedimentos de custeio estão embasados na pesquisa bibliográfica realizada nas obras de Martins (2003) e Marion (2005). 


\section{DETALHAMENTO DOS SERVIÇOS DE COLHEITA FLORESTAL}

Para cumprir os objetivos do estudo entende-se que as seguintes etapas devem ser cumpridas: (1) conhecer a estrutura organizacional de uma empresa que realiza este tipo de atividade, identificando os diferentes departamentos existentes e suas funções; (2) analisar quais são as características inerentes aos serviços prestados que impactam nos custos; (3) determinar o objeto de custeio e os principais elementos de custos envolvidos.

\section{ESTRUTURA OPERACIONAL DA EMPRESA TERCEIRIZADA}

As empresas prestadoras de serviços de colheita florestal realizam suas atividades na sede da empresa contratante, normalmente em hortos florestais afastados da cidade e de difícil acesso. Além da sede administrativa, faz-se necessário que uma estrutura seja montada no campo (local de trabalho) e que ofereça: (1) um espaço para os trabalhadores fazerem suas refeições e passar os períodos de descanso obrigatórios por lei; (2) local que abrigue o pessoal encarregado da vigilância; (3) oficina com recursos necessários (gerador de energia, aparelho de solda, torno, peças de reposição etc.) para que manutenções corretivas de pequeno porte sejam realizadas no campo, evitando perda de tempo e, logo, de produção, em caso de quebra de máquinas e (4) reservatório para armazenamento de combustível. Dado que os serviços são prestados em vários locais distintos, mudanças periódicas de acampamento são efetuadas. Por esta razão, as estruturas montadas são móveis (ônibus, trailers e containeres adaptáveis). A Figura 4 apresenta a estrutura operacional.

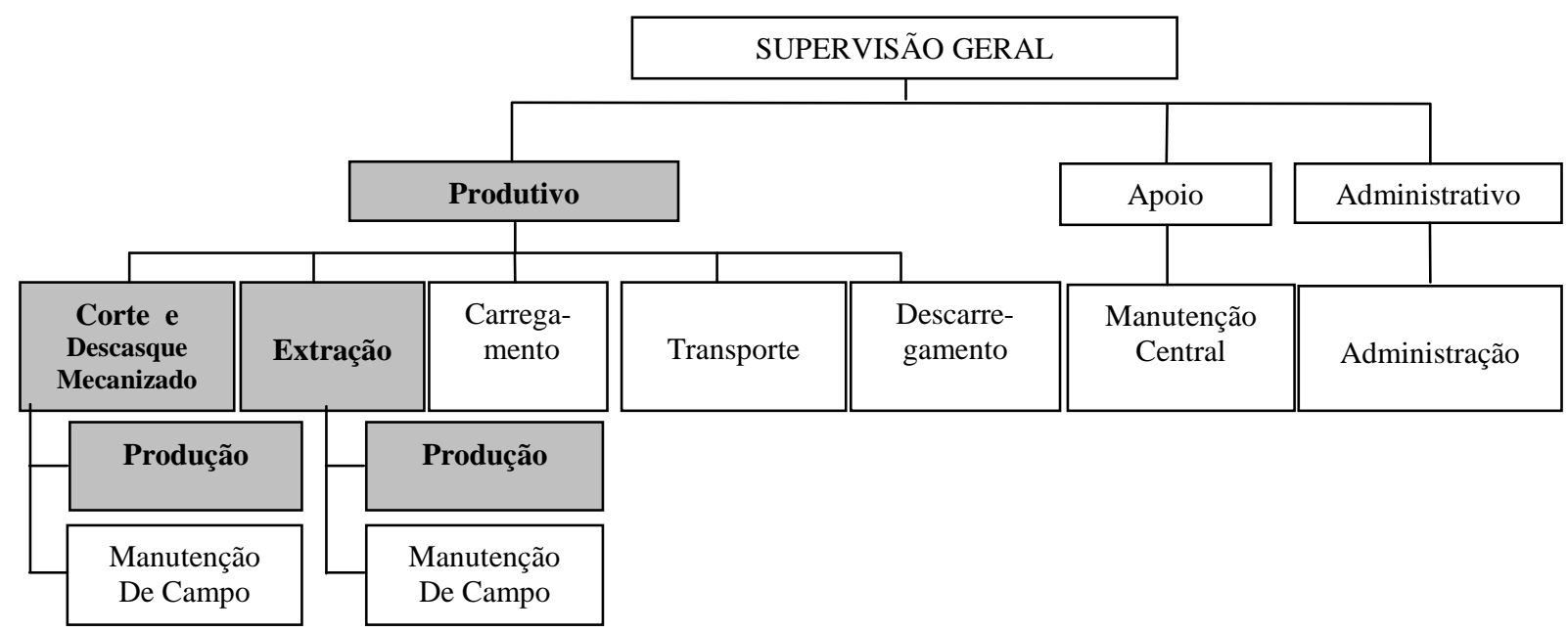

Figura 4: Organograma operacional da empresa prestadora dos serviços

A Figura 3 permite identificar os departamentos que no conjunto formam a empresa, a saber: (1) departamento produtivo: que compreende todas as etapas da colheita florestal; (2) departamento de apoio: composto por (a) departamento de manutenção de campo, que presta serviços especificamente para cada um dos departamentos produtivos e (b) departamento de manutenção central, que atende a todos 
os setores e que se localiza na cidade e (3) departamento administrativo: encarregado das atividades administrativas e comerciais da empresa. Os impactos ambientais são monitorados pela contratante, proprietária das florestas, certificada pela respectiva norma ISO e por órgãos governamentais específicos do setor florestal. A contratada, embora deva atender as normas de qualidade estabelecidas pela empresa contratante, não possui certificações ambientais.

\section{CARACTERÍSTICAS TÉCNICAS DOS SERVIÇOS DE CORTE E DESCASQUE}

O serviço é cobrado da empresa cliente por metro cúbico $\left(\mathrm{m}^{3}\right)$ de madeira; logo, a atividade tem como parâmetro físico a quantidade de $\mathrm{m}^{3}$ de madeira cortada, desgalhada, descascada e seccionada em toras de 3 metros de comprimento (serviço de corte e descasque mecanizado). Tal como em outras atividades, a colheita florestal possui variáveis que devem ser consideradas na mensuração e análise dos custos incorridos tais como: (1) volume individual das árvores; (2) distância do transporte; (3) comprimento das toras; (4) características do terreno e condições climáticas; (5) modelo dos equipamentos; (6) tempo de experiência e técnica dos operadores.

Todas as variáveis provocam algum tipo de impacto na produtividade dos equipamentos e nos custos, sendo a variável volume individual das árvores a mais relevante. De fato, características da floresta impactam diretamente nos custos do $\mathrm{m}^{3}$ de madeira, pois, quanto menor o volume da árvore, maior a quantidade de árvores necessária para se obter $1 \mathrm{~m}^{3}$ na forma desejada. Em uma floresta com um volume médio de $0,2550 \mathrm{~m}^{3}$ por árvore, é necessário cortar e descascar 3,92 árvores para que se obtenha $1 \mathrm{~m}^{3}$ de madeira $(1 / 0,2550=3,92)$; já em uma floresta com $0,1950 \mathrm{~m}^{3}$ por árvore é necessário, em média, 5,13 árvores para que se obtenha o mesmo $1 \mathrm{~m}^{3}(1 / 0,1950=5,13)$. Assim, se em uma hora de operação um equipamento cortar e descascar cerca de 75 árvores, sua produção é de $19,13 \mathrm{~m}^{3}$ para um volume médio de $0,2550 \mathrm{~m}^{3} /$ árvore, ou de $14,63 \mathrm{~m}^{3}$ para um volume médio de $0,1950 \mathrm{~m}^{3} /$ árvore. Esta questão de produtividade é mostrada no Quadro 2.

\begin{tabular}{|c|c|c|c|c|}
\hline $\begin{array}{c}\text { Volume } \\
\text { médio/árvore } \\
\left(\mathrm{m}^{3} / \text { árvore }\right)\end{array}$ & $\begin{array}{c}\text { Custo hora } \\
\text { operação máquina }\end{array}$ & $\begin{array}{c}\text { Quant. árvores } \\
\text { produzidas/h }\end{array}$ & $\begin{array}{c}\mathrm{m}^{3} \text { produzido / } \\
\text { hora }\end{array}$ & Custo do $\mathrm{m}^{3}$ \\
\hline Maior & Igual & Igual & Maior & Menor \\
\hline Menor & Igual & Igual & Menor & Maior \\
\hline
\end{tabular}

Quadro 2: Impactos do volume/árvore na produtividade e custo da

atividade de corte mecânico

Assim, para analisar os impactos da variação de volume/árvore no custo final do $\mathrm{m}^{3}$ de madeira colhida é necessário identificar o custo de 1 hora de operação do equipamento. Para tanto, a análise dos custos envolvidos na prestação dos serviços é feita da seguinte forma: (1) cada equipamento é considerado um centro de custo; (2) os custos são classificados (diretos, indiretos, fixos e variáveis) em relação ao equipamento; (3) os diretos são alocados ao equipamento; (4) os indiretos são apropriados aos equipamentos, obedecendo a base estabelecida; (5) obtém-se o custo hora de operação de cada equipamento; (6) obtém-se o custo de cada $\mathrm{m}^{3}$ madeira cortada e descascada. 


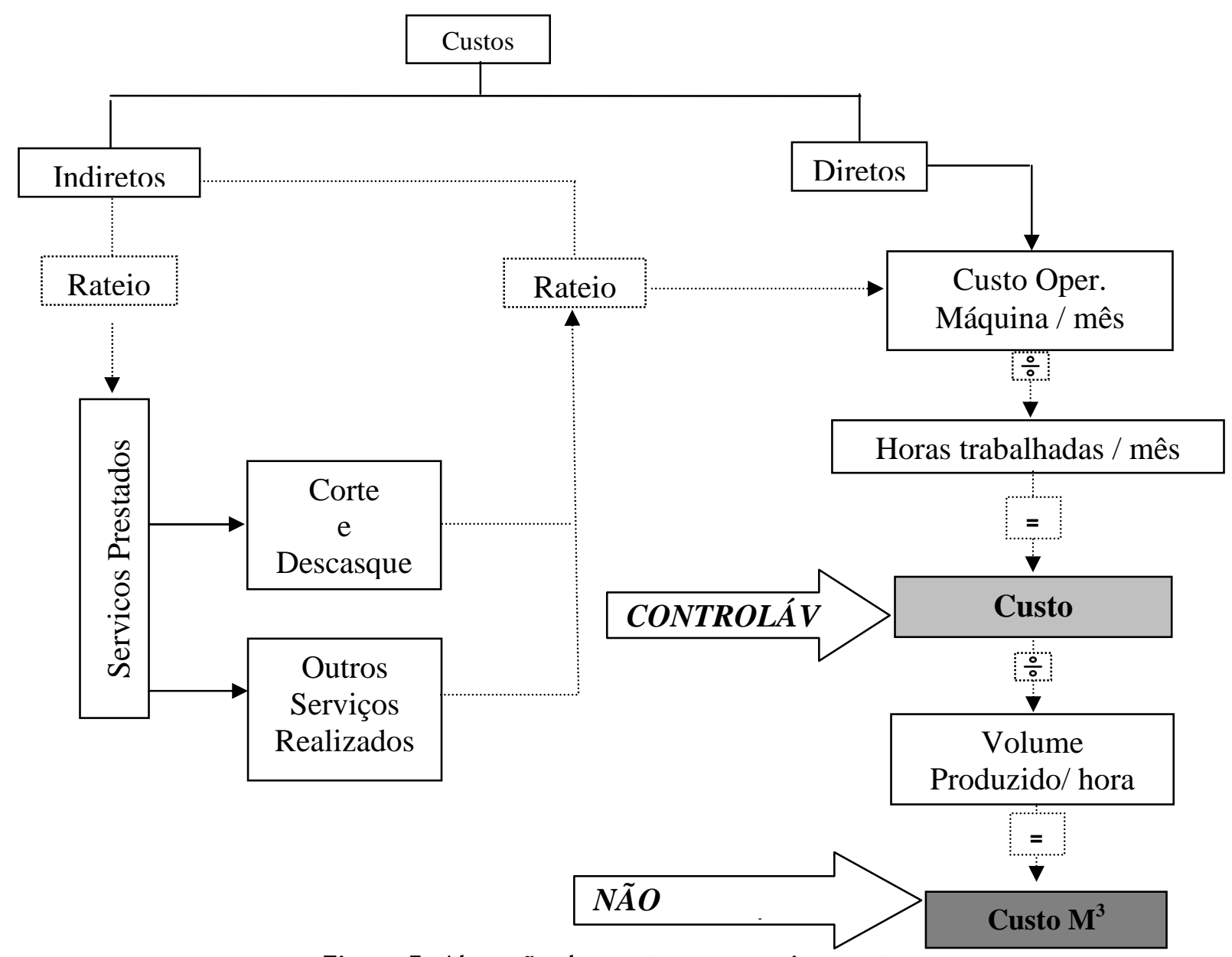

Figura 5: Alocação dos custos aos equipamentos

A classificação inicial dos custos em diretos e indiretos é assim efetuada: (1) custos indiretos em relação às atividades (centros de custos) e ao equipamento. Estes custos são apropriados em dois estágios: primeiro às atividades e, depois, aos equipamentos; (2) custos diretos em relação à atividade, mas indiretos em relação ao equipamento: também é necessária a utilização de bases de apropriação para que sejam alocados a eles. Mediante a divisão do custo total de operação do equipamento pelo total de horas trabalhadas no mês obtém-se o custo da hora/máquina. Entretanto, a base da receita cobrada é $\mathrm{o} \mathrm{m}^{3}$ de madeira cortada e descascada. Assim, calcula-se o custo do $\mathrm{m}^{3}$, pela divisão dos custos da hora/máquina pela quantidade de $\mathrm{m}^{3}$ produzidos em uma hora de operação (Figura 5).

Destaca-se que embora o custo da hora/máquina trabalhada seja controlável pela empresa, uma vez que há condições de gerenciar o total de recursos e horas/máquina efetivamente trabalhadas por equipamento, o custo do $\mathrm{m}^{3}$ está fora do seu controle porquanto o volume produzido por hora é determinado pelas características da floresta na qual o serviço é realizado.

Assim, dadas as características peculiares inerentes aos serviços prestados, o presente estudo busca identificar e caracterizar qual o modelo de apropriação dos custos incorridos que, além de permitir a mensuração do custo do $\mathrm{m}^{3}$ de madeira cortada e descascada mecanicamente, possibilite a análise e o gerenciamento dos custos controláveis e não controláveis. 


\section{OBJETO DE CUSTEIO E CUSTOS DOS SERVIÇOS}

Dado o objetivo de custear o $\mathrm{m}^{3}$ de madeira cortada e descascada, de início os custos são classificados e mensurados em função da hora/máquina trabalhada, sendo este, portanto, o objeto de custeio. Para entender a relação de cada um dos elementos de custo com o objeto de custeio (hora/máquina trabalhada), faz-se necessário classificá-los em custos diretos e indiretos (Figura 6).

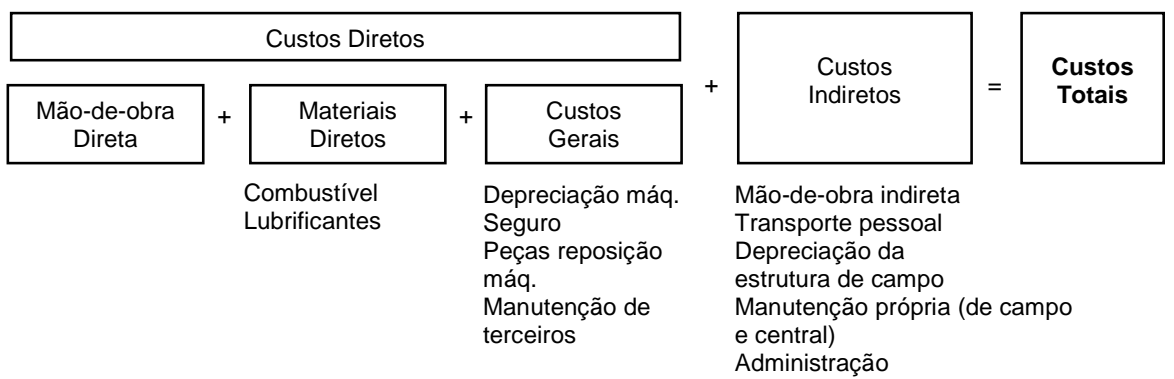

Figura 6: Custos diretos e indiretos em relação

à hora/máquina trabalhada

Na seqüência, identifica-se como eles ocorrem em relação ao objeto de custeio: determinar se são fixos ou variáveis. Aqui se considera custos fixos aqueles que não se alteram em função do número de horas/máquinas trabalhadas, e variáveis aqueles que sofrem alterações (Figura 7).

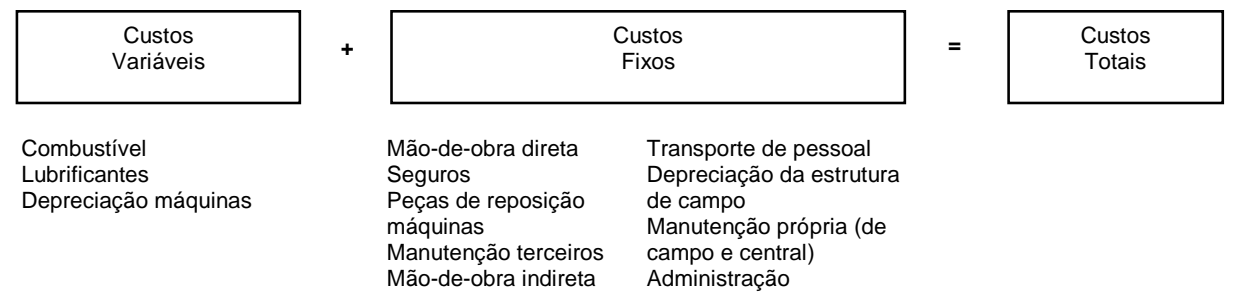

Figura 7: Custos fixos e variáveis em relação

à hora/máquina trabalhada

Os custos dos departamentos de apoio, indiretos não apenas em relação às máquinas, mas também às atividades, são assim alocados: (1) administração: distribuídos entre os demais departamentos com base nos respectivos números de funcionários; (2) manutenção central: alocados a cada uma das máquinas com base no número de horas de manutenção de cada uma delas.

0 tratamento dos custos indiretos em relação às máquinas, mas diretos em relação aos departamentos produtivos é o seguinte: (1) custos do departamento: diz respeito aos custos com supervisão, deslocamento dos funcionários e depreciação das estruturas de campo, sendo alocado a cada equipamento em função do número de máquinas existentes; 
(2) manutenção de campo: distribuídos entre as máquinas com base no número de horas gastas com manutenção.

A seção seguinte demonstra de que forma ocorre a mensuração do custo do $\mathrm{m}^{3}$ de madeira cortada e descascada.

\section{MENSURAÇÃO DOS CUSTOS}

\section{Custos diretos da atividade de corte e descasque mecanizada}

$\mathrm{Na}$ atividade de corte e descasque mecanizada a mensuração dos custos é realizada com base nas seguintes premissas: (1) equipamentos: a empresa opera com máquinas que possuem as características relacionadas na Tabela 3.

Tabela 3: Características do equipamento utilizado

\begin{tabular}{|l|r|r|}
\multicolumn{1}{c|}{ Dados } & Escavadeira & \multicolumn{1}{c|}{ Cabeçote } \\
\hline Custo aquisição (\$) & $680.000,00$ & $262.000,00$ \\
\hline Valor residual (\$) & $180.000,00$ & 0,00 \\
\hline Vida útil (horas trabalhadas) & 25.000 & 12.500 \\
\hline Consumo combustível (l/hora) & \multicolumn{2}{|c|}{20,00} \\
\hline Consumo óleo lubrificante & \multicolumn{2}{|c|}{$30 \%$ do custo com combustível }
\end{tabular}

(2) total de horas trabalhadas/mês: a empresa opera em 3 turnos de 8 horas cada, 26 dias por mês (30 dias menos 4 domingos). A utilidade operacional dos equipamentos é de 70\%: o restante (30\%) é usado para manutenção/abastecimento do equipamento e repouso/alimentação do operador. Assim, o total de horas/máquina do mês é assim obtido: 24 horas $\times 26$ dias = 624 horas; 624 horas $\times 70 \%=436,8$ horas $/$ mês. 0 total de horas trabalhadas no mês varia de acordo com a idade do equipamento: quanto mais velho for, menor a disponibilidade dado o tempo com manutenções, principalmente corretivas. Considera-se que a empresa opera com os 3 seguintes equipamentos (Tabela 4):

Tabela 4: Características das máquinas

\begin{tabular}{|l|c|c|c|}
\multicolumn{1}{|c|}{ Dados } & Máquina 1 & Máquina 2 & Máquina 3 \\
\hline Idade máquina (em anos) & 3,0 & 1,0 & 0,5 \\
\hline $\begin{array}{l}\text { Total de horas efetivamente } \\
\text { trabalhadas no mês }\end{array}$ & 343,20 & 436,80 & 436,80 \\
\hline Disponibilidade operacional & $55 \%$ & $70 \%$ & $70 \%$ \\
\hline Horas gastas com manutenção: & & & 52 \\
\hline Central & 60,4 & 78 & 78 \\
\hline Campo & 90,6 & $7.822,00$ & $7.822,00$ \\
\hline Peças reposição (\$/mês) & $30.000,00$ & & \\
\hline
\end{tabular}

$\mathrm{Na}$ colheita mecanizada, o corte e descasque é realizado por um equipamento denominado harvester, composto por dois componentes: uma máquina-base de esteiras e um cabeçote processador. Com vida útil diferente, a depreciação é calculada individualmente (Tabela 5). 
Tabela 5: Cálculo da depreciação

\begin{tabular}{|l|r|r|}
\multicolumn{1}{|c|}{ Dados } & \multicolumn{1}{c|}{ Máquina-base } & \multicolumn{1}{c|}{ Cabeçote } \\
\hline Custo aquisição (\$) & $680.000,00$ & $262.000,00$ \\
\hline Valor residual (\$) & $180.000,00$ & 0,00 \\
\hline Vida útil (em horas) & 25.000 & 12.500 \\
\hline Valor depreciação (\$/hora trabalhada) & 20,00 & 20,96 \\
\hline
\end{tabular}

Dessa forma, levando-se em consideração o número de horas trabalhadas no mês, tem-se o seguinte custo de depreciação dos equipamentos (Tabela 6).

Tabela 6: depreciação por equipamento

\begin{tabular}{|l|r|r|r|}
\multicolumn{1}{|c|}{ Dados } & \multicolumn{1}{c|}{ Máquina 1 } & \multicolumn{1}{c|}{ Máquina 2 } & \multicolumn{1}{c|}{ Máquina 3 } \\
\hline Depreciação (\$/hora trabalhada) & 40,96 & 40,96 & 40,96 \\
\hline $\begin{array}{l}\text { Total de horas efetivamente trabalhadas no } \\
\text { mês }\end{array}$ & 343,20 & 436,80 & 436,80 \\
\hline Total depreciação (\$/mês) & $14.057,00$ & $17.891,00$ & $17.891,00$ \\
\hline
\end{tabular}

Ressalta-se que na empresa, para fins gerenciais, a depreciação não é calculada com base em uma taxa fixa, mas sim com base no número de horas utilizadas na produção, apuradas pelo horímetro do equipamento, resultando a quantidade total de horas correspondentes à sua vida útil. Com base nos dados fornecidos, os custos diretos de um mês de operação compõem-se do seguinte:

Tabela 7: Custos diretos de operação de cada equipamento/mês

\begin{tabular}{|l|r|r|r|r|r|}
\hline \multicolumn{1}{|c|}{ Descrição } & CF/ & \multicolumn{1}{c|}{ Máquina 1 } & \multicolumn{1}{c|}{ Máquina 2 } & \multicolumn{1}{c|}{ Máquina 3 } & \multicolumn{1}{c|}{ Total } \\
\hline Custos Diretos & & $\underline{\mathbf{7 0 . 1 5 5 , 0 0}}$ & $\underline{\mathbf{5 6 . 3 6 0 , 0 0}}$ & $\underline{\mathbf{5 6 . 3 6 0 , 0 0}}$ & $\underline{\mathbf{1 8 2 . 8 7 5 , 0 0}}$ \\
\hline Mão-de-obra direta & & $\mathbf{5 . 9 1 1 , 0 0}$ & $\mathbf{5 . 9 1 1 , 0 0}$ & $\mathbf{5 . 9 1 1 , 0 0}$ & $\mathbf{1 7 . 7 3 3 , 0 0}$ \\
\hline Materiais diretos & & $\mathbf{1 6 . 6 8 7 , 0 0}$ & $\mathbf{2 1 . 2 3 6 , 0 0}$ & $\mathbf{2 1 . 2 3 6 , 0 0}$ & $\mathbf{5 9 . 1 5 9 , 0 0}$ \\
\hline Combustível & CV & $12.836,00$ & $16.336,00$ & $16.336,00$ & $45.508,00$ \\
\hline Lubrificantes & CV & $3.851,00$ & $4.900,00$ & $4.900,00$ & $13.651,00$ \\
\hline Gerais & & $\mathbf{4 7 . 5 5 7 , 0 0}$ & $\mathbf{2 9 . 2 1 3 , 0 0}$ & $\mathbf{2 9 . 2 1 3 , 0 0}$ & $\mathbf{1 0 5 . 9 8 3 , 0 0}$ \\
\hline Depreciação máquinas & CV & $14.057,00$ & $17.891,00$ & $17.891,00$ & $49.839,00$ \\
\hline Seguro & CF & 500,00 & 500,00 & 500,00 & $1.500,00$ \\
\hline Peças reposição máquinas & CF & $30.000,00$ & $7.822,00$ & $7.822,00$ & $45.644,00$ \\
\hline Manutenção de terceiros & CF & $3.000,00$ & $3.000,00$ & $3.000,00$ & $9.000,00$ \\
\hline
\end{tabular}

\section{Custos indiretos}

Como já mencionado, os custos que não podem ser identificados diretamente com cada um dos equipamentos são alocados através de rateio. Ressalta-se o reconhecimento das distorções provocadas pelos rateios devido à sua subjetividade. Portanto, a utilização de rateio para alocação dos custos indiretos representa uma limitação do modelo proposto neste estudo.

Como forma de amenizar tais distorções, adota-se os critérios que, acredita-se, melhor reflitam o consumo dos recursos por cada um dos equipamentos (Quadro 3). 


\begin{tabular}{|l|l|}
\multicolumn{1}{|c|}{ Custos Indiretos } & \multicolumn{1}{c|}{ Critério Rateio } \\
\hline Departamento administração & Número de funcionários \\
\hline Departamento de Manutenção Central & Horas gastas com manutenção \\
\hline Custos do departamento & Número de equipamentos \\
\hline Departamento de Manutenção de Campo & Horas gastas com manutença \\
\hline \multicolumn{1}{|c|}{ Quadro 3: Critérios de rateio adotados }
\end{tabular}

Quadro 3: Critérios de rateio adotados

Assim, os custos indiretos são alocados aos equipamentos das atividades de Corte e Descasque como demonstra a Tabela 8. 
Tabela 8: Mapa de localização de custos

\begin{tabular}{|c|c|c|c|c|c|c|c|c|}
\hline \multirow[b]{2}{*}{ CUSTOS INDIRETOS } & \multicolumn{2}{|c|}{ APOIO } & \multicolumn{6}{|c|}{ CORTE E DESCASQUE } \\
\hline & 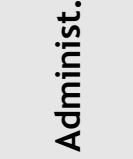 & 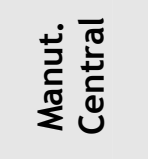 & 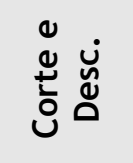 & 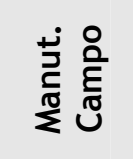 & $\overline{\dot{\sigma}}$ & 焉 & $\begin{array}{l}m \\
\dot{\sigma} \\
\frac{\pi}{\Sigma}\end{array}$ & $\frac{\text { 衣 }}{\text { o }}$ \\
\hline Mão-de-obra e enc. & 28.550 & 9.075 & 2.941 & 7.200 & & & & 47.766 \\
\hline Energia elétrica & 350 & 800 & - & - & & & & 1.150 \\
\hline Água & 150 & 250 & - & - & & & & 400 \\
\hline Telefone & 1.500 & 200 & - & - & & & & 1.700 \\
\hline Aluguel & 1.200 & 3.300 & - & - & & & & 4.500 \\
\hline Contabilidade & 3.500 & - & - & - & & & & 3.500 \\
\hline Depreciação & 1.400 & 2.500 & 420 & 800 & & & & 5.120 \\
\hline Transporte Pessoal & - & - & 3.800 & 1.200 & & & & 5.000 \\
\hline Combustível & 1.500 & 1.500 & - & - & & & & 3.000 \\
\hline Outros custos & 1.850 & 1.500 & - & 800 & & & & 4.150 \\
\hline Total & 40.000 & 19.125 & 7.161 & 10.000 & - & - & - & $\begin{array}{r}76.28 \\
6\end{array}$ \\
\hline $\begin{array}{l}\text { Rateio } 1 \text { - } \\
\text { Administração }\end{array}$ & & 5 & 15 & 5 & - & - & - & - \\
\hline $\begin{array}{l}\text { B. de rateio }-n^{\circ} \text {. } \\
\text { func. }\end{array}$ & $\begin{array}{r}(40.000 \\
)\end{array}$ & 8.000 & 24.000 & 8.000 & - & - & - & - \\
\hline Total 1 & - & 27.125 & 31.161 & 18.000 & - & - & - & $\begin{array}{r}76.28 \\
6\end{array}$ \\
\hline $\begin{array}{l}\text { Rateio } 2 \text { - Man. } \\
\text { Central }\end{array}$ & - & & & & 60,4 & 52 & 52 & \\
\hline $\begin{array}{l}\text { B. de rateio - } h \text {. } \\
\text { man. }\end{array}$ & - & $\begin{array}{r}(27.125 \\
)\end{array}$ & - & - & 9.965 & 8.580 & 8.580 & \\
\hline Total 2 & - & - & 31.161 & 18.000 & 9.965 & 8.580 & 8.580 & $\begin{array}{r}76.28 \\
6 \\
\end{array}$ \\
\hline $\begin{array}{l}\text { Rateio } 3 \text { - Custos do } \\
\text { Departamento }\end{array}$ & - & - & & & 1 & 1 & 1 & \\
\hline $\begin{array}{l}\text { B. de rateio - } \mathrm{n}^{\circ} \text {. } \\
\text { equip. }\end{array}$ & - & - & $\begin{array}{r}(31.161 \\
)\end{array}$ & - & $\begin{array}{r}10.38 \\
7\end{array}$ & $\begin{array}{r}10.38 \\
7\end{array}$ & $\begin{array}{r}10.38 \\
7\end{array}$ & - \\
\hline Total 3 & - & - & - & 18.000 & $\begin{array}{r}20.35 \\
2\end{array}$ & $\begin{array}{r}18.96 \\
7\end{array}$ & $\begin{array}{r}18.96 \\
7\end{array}$ & $\begin{array}{r}76.28 \\
6\end{array}$ \\
\hline $\begin{array}{l}\text { Rateio } 4 \text { - Man. de } \\
\text { Campo }\end{array}$ & & - & - & & 90,6 & 78 & 78 & \\
\hline $\begin{array}{l}\text { B. de rateio - } \mathrm{h} \text {. } \\
\text { man. }\end{array}$ & - & - & - & $\begin{array}{r}(18.000 \\
)\end{array}$ & 6.612 & 5.694 & 5.694 & - \\
\hline $\begin{array}{l}\text { Total custos } \\
\text { indiretos }\end{array}$ & - & - & - & - & $\begin{array}{r}26.96 \\
4 \\
\end{array}$ & $\begin{array}{r}24.66 \\
1 \\
\end{array}$ & $\begin{array}{r}24.66 \\
1 \\
\end{array}$ & $\begin{array}{r}76.28 \\
6 \\
\end{array}$ \\
\hline Total custos diretos & - & - & - & - & $\begin{array}{r}70.15 \\
5\end{array}$ & $\begin{array}{r}56.36 \\
0 \\
\end{array}$ & $\begin{array}{r}56.36 \\
0 \\
\end{array}$ & $\begin{array}{r}182.8 \\
75 \\
\end{array}$ \\
\hline CUSTO TOTAL & - & - & - & - & $\begin{array}{r}97.19 \\
9\end{array}$ & $\begin{array}{r}81.02 \\
1\end{array}$ & $\begin{array}{r}81.02 \\
1\end{array}$ & $\begin{array}{r}259.1 \\
61\end{array}$ \\
\hline $\begin{array}{l}\text { Total de horas } \\
\text { trabalhadas }\end{array}$ & - & - & - & - & 343,2 & 436,8 & 436,8 & $\begin{array}{r}1.216 \\
8\end{array}$ \\
\hline $\begin{array}{l}\text { CUSTO HORA MÁQ. } \\
\text { TRAB. }\end{array}$ & - & & & - & $\begin{array}{r}282,9 \\
8\end{array}$ & $\begin{array}{r}185,4 \\
9\end{array}$ & $\begin{array}{r}185,4 \\
9\end{array}$ & $\begin{array}{r}212,9 \\
9\end{array}$ \\
\hline
\end{tabular}


Com os dados da Tabela 8, através da soma dos custos indiretos rateados aos equipamentos, mais os custos diretos apurados na Tabela 7 , obtém-se o custo total de operação de cada máquina. $\mathrm{E}$, dividindo-se esse custo total pelo número de horas trabalhadas durante o mês, apura-se o custo da hora/máquina. Porém, ainda é necessário apurar o custo do $\mathrm{m}^{3}$ base do faturamento.

Adaptando-se a lógica do Quadro 2, é possível determinar o custo médio do $\mathrm{m}^{3} \mathrm{da}$ madeira cortada e descascada: divide-se o custo médio hora/operação pelo $\mathrm{m}^{3}$ produzido/hora, considerando-se o impacto do volume das árvores no custo final do serviço prestado.

Tabela 9: Impacto do tipo do volume no custo médio do $\mathrm{m}^{3}$ de madeira

\begin{tabular}{|c|c|c|c|c|c|c|c|c|c|c|}
\hline \multirow{3}{*}{$\begin{array}{c}\text { Situação } \\
1 \\
\end{array}$} & \multicolumn{2}{|c|}{$\begin{array}{l}\text { Volume/árvore } \\
\text { (m³/árvore) }\end{array}$} & \multicolumn{2}{|c|}{$\begin{array}{l}\text { Custo médio hora } \\
\text { operação máq. } \\
\text { (\$) }\end{array}$} & \multicolumn{2}{|c|}{$\begin{array}{c}\text { Quantidade } \\
\text { árvores } \\
\text { produzidas/hora }\end{array}$} & \multicolumn{2}{|c|}{$\begin{array}{c}\mathrm{m}^{3} \text { produzido/ } \\
\text { hora }\end{array}$} & \multicolumn{2}{|c|}{$\begin{array}{l}\text { Custo Médio } \\
\text { do } \mathrm{m}^{3}(\$)\end{array}$} \\
\hline & Maior & 0,2550 & Igual & 212,99 & Igual & 75 & Maior & 19,13 & Menor & 11,14 \\
\hline & Menor & 0,1950 & Igual & 212,99 & Igual & 75 & Menor & 14,63 & Maior & 14,56 \\
\hline
\end{tabular}

Observa-se que o custo final do $\mathrm{m}^{3}$ de madeira sofre influência direta do volume das árvores colhidas: quanto menor o volume/árvore, maior o custo do $\mathrm{m}^{3}$. Sabendo-se que as características da floresta não são fatores controlados pela prestadora de serviços, algumas análises são necessárias para que ela possa gerenciar seus custos, bem como identificar pontos de controle e negociar o preço de venda. Para isso segregam-se os impactos das peculiaridades da floresta (não controláveis) e dos efeitos da ineficiência (controláveis) no custo e, por conseqüência, no resultado.

\section{ANÁLISE DOS CUSTOS E RESULTADOS}

\section{CUSTOS DO SERVIÇO DE CORTE E DESCASQUE}

Para fins de análise, as seguintes premissas são adotadas: (1) preço de venda líquido (sem impostos) do serviço realizado: $\$ 15,00 / \mathrm{m}^{3}$ de madeira cortada e descascada; (2) o custo dos serviços prestados é classificado em custo fixo e variável, conforme Tabela 10: 
Tabela 10: Custos fixos e variáveis/mês

\begin{tabular}{|l|r|r|r|r|r|}
\hline \multicolumn{1}{|c|}{ Descrição } & $\begin{array}{c}\text { CD/ } \\
\text { CI }\end{array}$ & Máquina 1 & Máquina 2 & Máquina 3 & \multicolumn{1}{c|}{$\begin{array}{c}\text { Custo Total } \\
\mathbf{( \$ )}\end{array}$} \\
\hline Custos Variáveis & & $\underline{\mathbf{3 0 . 7 4 4 , 0 0}}$ & $\underline{\mathbf{3 9 . 1 2 7 , 0 0}}$ & $\underline{\mathbf{3 9 . 1 2 7 , 0 0}}$ & $\underline{\mathbf{1 0 8 . 9 9 8 , 0 0}}$ \\
\hline Combustível & $\mathrm{CD}$ & $12.836,00$ & $16.336,00$ & $16.336,00$ & $45.508,00$ \\
\hline Lubrificantes & $\mathrm{CD}$ & $3.851,00$ & $4.900,00$ & $4.900,00$ & $13.651,00$ \\
\hline Depreciação máquinas & $\mathrm{CD}$ & $14.057,00$ & $17.891,00$ & $17.891,00$ & $49.839,00$ \\
\hline Custos Fixos & & $\underline{\mathbf{6 6 . 3 7 5 , 0 0}}$ & $\underline{\mathbf{4 1 . 8 9 4 , 0 0}}$ & $\underline{\mathbf{4 1 . 8 9 4 , 0 0}}$ & $\underline{\mathbf{1 5 0 . 1 6 3 , 0 0}}$ \\
\hline Mão-de-obra direta & $\mathrm{CD}$ & $5.911,00$ & $5.911,00$ & $5.911,00$ & $17.733,00$ \\
\hline Seguro & $\mathrm{CD}$ & 500,00 & 500,00 & 500,00 & $1.500,00$ \\
\hline Peças reposição máquinas & $\mathrm{CD}$ & $30.000,00$ & $7.822,00$ & $7.822,00$ & $45.644,00$ \\
\hline Manutenção de terceiros & $\mathrm{CD}$ & $3.000,00$ & $3.000,00$ & $3.000,00$ & $9.000,00$ \\
\hline Custos Indiretos & $\mathrm{Cl}$ & $26.964,00$ & $24.661,00$ & $24.661,00$ & $\mathbf{7 6 . 2 8 6 , 0 0}$ \\
\hline Custo Total & & $\underline{\mathbf{9 7 . 1 9 9 , 0 0}}$ & $\underline{\mathbf{8 1 . 0 2 1 , 0 0}}$ & $\underline{\mathbf{8 1 . 0 2 1 , 0 0}}$ & $\underline{\mathbf{2 5 9 . 1 6 1 , 0 0}}$ \\
\hline
\end{tabular}

Sabe-se também que a empresa opera com 3 máquinas e as análises realizadas a seguir são feitas considerando-se as seguintes situações, extraídas do Quadro 2: (a) situação 1: a floresta possui árvores com volume médio de $0,255 \mathrm{~m}^{3} /$ árvore e produz 19,13 $\mathrm{m}^{3}$ /hora; (b) situação 2: a floresta possui árvores com volume médio de $0,195 \mathrm{~m}^{3} /$ árvore e produz $14,63 \mathrm{~m}^{3} /$ hora. No caso estudado, a floresta descrita na situação 1 possui as características ideais de operação.

Para simplificação, os cálculos são realizados com base no volume médio/árvore. 0 volume varia entre as árvores e é medido pelos sensores eletrônicos do equipamento que, ao final de cada turno, imprime um relatório sobre o total de árvores processadas e a quantidade de $\mathrm{m}^{3}$ produzida.

Adicionalmente, observa-se que a produção realizada por cada uma das máquinas não é uniforme, pois a disponibilidade operacional e a experiência do operador são diferenciadas. Assim, o estudo considera que a Máquina 1, como já demonstrado, tem uma disponibilidade inferior às demais e que a Máquina 3 , embora possua condições de operação similares à Máquina 2, é operada por funcionários menos experientes, o que resulta em uma redução de $10 \%$ do $\mathrm{m}^{3}$ /hora produzido. Assim, considerando-se que o serviço seja prestado em uma floresta em condições ideais de operação, a produção de cada um dos equipamentos, durante o mês, é a seguinte:

Tabela 11: Produção por máquina/mês - (situação 1)

\begin{tabular}{l|r|r|r|r|} 
& \multicolumn{1}{|c|}{ Máquina 1 } & \multicolumn{1}{c|}{ Máquina 2 } & \multicolumn{1}{c|}{ Máquina 3 } & \multicolumn{1}{c|}{ Total } \\
\hline Produção (m³/hora) & 19,13 & 19,13 & 17,21 & - \\
\hline Horas trabalh. / mês & 343,20 & 436,80 & 436,80 & $1.216,80$ \\
\hline Produção total (m ${ }^{3}$ /hora) & $6.563,70$ & $8.353,80$ & $7.518,42$ & $22.435,92$ \\
\hline $\begin{array}{l}\text { Participação na Produção } \\
\text { (\%) }\end{array}$ & $29,26 \%$ & $37,23 \%$ & $33,51 \%$ & $100,00 \%$ \\
\end{tabular}

A Tabela 12 mostra a produção realizada por cada equipamento, quando o serviço é realizado em florestas cujo volume/árvore está abaixo do ideal (situação 2): 
Tabela 12: Produção por máquina/mês - (situação 2)

\begin{tabular}{l|r|r|r|r|} 
& \multicolumn{1}{|c|}{ Máquina 1 } & \multicolumn{1}{c|}{ Máquina 2 } & \multicolumn{1}{c|}{ Máquina 3 } & \multicolumn{1}{c|}{ Total } \\
\hline Produção $\left(\mathrm{m}^{3} /\right.$ hora) & 14,63 & 14,63 & 13,16 & - \\
\hline Horas trabalh. / mês & 343,2 & 436,8 & 436,8 & $1.216,80$ \\
\hline Produção total (m ${ }^{3} /$ hora) & $5.019,30$ & $6.388,20$ & $5.749,38$ & $17.156,88$ \\
\hline Participação na Produção (\%) & $29,26 \%$ & $37,23 \%$ & $33,51 \%$ & $100,00 \%$ \\
\hline
\end{tabular}

\section{ANÁLISE DO RESULTADO DO SERVIÇO - SITUAÇÕES 1 E 2 COM INEFICIÊNCIAS}

Com base nos dados apresentados, a margem de contribuição e o resultado operacional do serviço de corte e descasque são os seguintes (Tabelas 13 e 14).

Tabela 13: Resultado operacional - (situação 1)

\begin{tabular}{|c|c|c|c|}
\hline Descrição & Total & Hora & $M^{3}$ \\
\hline Horas trabalhadas & $1.216,80$ & $1.216,80$ & \\
\hline Quantidade prod. $\left(\mathrm{m}^{3}\right)$ & $22.435,92$ & & $22.435,92$ \\
\hline Prod. média hora/trabalh. $\left(\mathrm{m}^{3}\right)$ & 18,44 & & \\
\hline $\begin{array}{l}\text { Receita hora/trabalhada } \\
\text { Receita por } \mathrm{m}^{3}\end{array}$ & $\begin{array}{r}276,58 \\
15,00\end{array}$ & & \\
\hline Receita Vendas & $336.538,80$ & 276,58 & 15,00 \\
\hline (-) Custos variáveis & $(108.998,00)$ & $(89,58)$ & $(4,86)$ \\
\hline Margem Contribuição & $227.540,80$ & 187,00 & 10,14 \\
\hline Margem Contribuição \% & $67,61 \%$ & $67,61 \%$ & $67,61 \%$ \\
\hline (-) Custos Fixos & $(150.163,00)$ & $(123,41)$ & $(6,69)$ \\
\hline Resultado Operacional & $77.377,80$ & 63,59 & 3,45 \\
\hline Margem operacional \% & $22,99 \%$ & $22,99 \%$ & $22,99 \%$ \\
\hline
\end{tabular}

Tabela 14: Resultado operacional - (situação 2)

\begin{tabular}{|c|c|c|c|}
\hline Descrição & Total & Hora & $M^{3}$ \\
\hline Horas trabalhadas & $1.216,80$ & $1.216,80$ & \\
\hline Quantidade prod. $\left(\mathrm{m}^{3}\right)$ & $17.156,88$ & & $17.156,88$ \\
\hline Prod. média hora/trabalh. $\left(\mathrm{m}^{3}\right)$ & 14,10 & & \\
\hline Receita hora/trabalhada & 211,50 & & \\
\hline Preço por $\mathrm{m}^{3}$ & 15,00 & & \\
\hline Receita vendas & $257.353,20$ & 211,50 & 15,00 \\
\hline (-) Custos variáveis & $(108.998,00)$ & $(89,58)$ & $(6,35)$ \\
\hline Margem Contribuição & $148.355,20$ & 121,92 & 8,65 \\
\hline Margem Contribuição \% & $57,65 \%$ & $57,65 \%$ & $57,65 \%$ \\
\hline (-) Custos Fixos & $(150.163,00)$ & $(123,41)$ & $(8,75)$ \\
\hline Resultado Operacional & $(1.807,80)$ & $(1,49)$ & $(0,11)$ \\
\hline Margem operacional \% & $-0,70 \%$ & $-0,70 \%$ & $-0,70 \%$ \\
\hline
\end{tabular}

Assim, em condições idênticas de operação, a diferença de volume das árvores cortadas e descascadas causou a expressiva redução de $14,7 \%$ na contribuição de cobertura unitária (de $\$ 10,14$ para $\$ 8,65$ ), além da redução de $30,9 \%$ na absorção dos custos fixos (de $\$ 6,69$ para $\$ 8,75)$. Em conseqüência, o lucro operacional é muito afetado, passando de $\$ 77.377$ para um prejuízo de $\$ 1.807$. Isso ocorre porque os custos e despesas incorridos são 
iguais nas duas situações, bem como o número de horas/máquina trabalhadas. Por outro lado, a receita total diminui em função do menor volume de $\mathrm{m}^{3}$ de madeira cortada e descascada. Considerando-se que os volumes variam, mas os custos permanecem inalterados, o ideal é que a empresa negocie seus preços de venda com base nas características da floresta, caso deseje obter na situação 2 o mesmo lucro obtido na 1.

\section{ANÁLISE DO RESULTADO DO SERVIÇO - TRATAMENTO DAS INEFICIÊNCIAS}

Conforme demonstra a Tabela 15, para obter a mesma margem de lucro obtida na situação 1 , a empresa deve obter um reajuste de $30,8 \%$ no preço do serviço realizado (de $\$$ $15,00$ para $\$ 19,62)$.

Tabela 15: Preço de venda - (margem de lucro desejada)

\begin{tabular}{|l|c|c|r|r|}
\hline \multicolumn{1}{|c|}{ Descrição } & $\begin{array}{c}\text { Custo Total / } \\
\text { mês }\end{array}$ & $\begin{array}{c}\text { Produção / } \\
\text { mês }\end{array}$ & $\begin{array}{c}\text { Custo Unit. / } \\
\text { mês }\end{array}$ & \multicolumn{1}{|c|}{ Valor } \\
\hline Custos variáveis & $108.998,00$ & $17.156,88$ & 6,35 & \\
\hline Custos Fixos & $150.163,00$ & $17.156,88$ & 8,75 & 15,00 \\
\hline Custo Total Unitário (\$) & & & & $22,99 \%$ \\
\hline Margem Lucro desejada & & & & 19,62 \\
\hline Preço de Venda Mínimo (\$) & & & & \\
\hline
\end{tabular}

Neste ponto, cabe ressaltar que realizando os cálculos como apresentado na Tabela 15, a empresa repassa ao cliente, além dos impactos causados por fatores que não pode controlar (características da floresta), os custos relacionados à sua própria ineficiência, decorrentes da baixa disponibilidade de um de seus equipamentos (Máquina 1) e pela inabilidade de seus funcionários (Máquina 3).

Considerando-se que ao embutir no cálculo do novo preço de venda o custo de sua ineficiência, a empresa corre o risco de ofertar um produto com preços superiores aos proporcionados pelos concorrentes, o que pode resultar na perda do contrato, outra análise importante que deve ser realizada refere-se ao reflexo desta ineficiência no custo final dos serviços prestados.

Neste estudo, supõe-se que a produção realizada pela Máquina 2, bem como os custos incorridos durante o mês, estão dentro dos níveis de eficiência aceitáveis e podem, portanto, serem utilizados como padrões para cálculo do preço de venda a ser praticado pela empresa.

A Tabela 16 demonstra a produção total realizada no mês, considerando-se que todos os equipamentos da empresa operam em condições idênticas às condições de operação da Máquina 2.

Tabela 16: Produção por máquina / mês - (sem ineficiência)

\begin{tabular}{|l|r|r|r|r|} 
& Máquina 1 & Máquina 2 & \multicolumn{1}{|c|}{ Máquina 3 } & \multicolumn{1}{|c|}{ Total } \\
\hline Produção $\left(\mathrm{m}^{3} /\right.$ hora $)$ & 14,63 & 14,63 & 14,63 & - \\
\hline Horas trab. / mês & 436,8 & 436,8 & 436,8 & $1.310,40$ \\
\hline Produção total $\left(\mathrm{m}^{3} /\right.$ hora) & $6.388,20$ & $6.388,20$ & $6.388,20$ & $19.164,60$ \\
\hline Produção $(\%)$ & $33,33 \%$ & $33,33 \%$ & $33,33 \%$ & $100,00 \%$ \\
\hline
\end{tabular}


$\mathrm{Na}$ Tabela 17 são apresentados os custos incorridos durante o mês, também se levando em consideração os níveis de consumo apresentados pela Máquina 2, considerados dentro do padrão aceitável, como já mencionado. 
Tabela 17: Mapa de localização de custos

\begin{tabular}{|c|c|c|c|c|c|c|c|c|}
\hline \multirow[b]{2}{*}{ CUSTOS INDIRETOS } & \multicolumn{2}{|c|}{ APOIO } & \multicolumn{6}{|c|}{ CORTE E DESCASQUE } \\
\hline & 苞 & 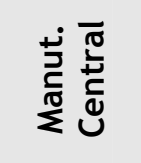 & 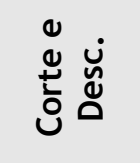 & 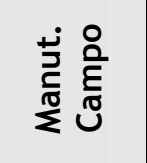 & $\overline{\check{\sigma}}$ & $\stackrel{N}{\stackrel{\sim}{\mathscr{T}}}$ & m & $\begin{array}{l}\frac{1}{5} \\
\text { 을 }\end{array}$ \\
\hline Mão-de-obra e enc. & 28.550 & 9.075 & 2.941 & 7.200 & & & & 47.766 \\
\hline Energia elétrica & 350 & 800 & - & - & & & & 1.150 \\
\hline Água & 150 & 250 & - & - & & & & 400 \\
\hline Telefone & 1.500 & 200 & - & - & & & & 1.700 \\
\hline Aluguel & 1.200 & 3.300 & - & - & & & & 4.500 \\
\hline Contabilidade & 3.500 & & - & - & & & & 3.500 \\
\hline Depreciação & 1.400 & 2.500 & 420 & 800 & & & & 5.120 \\
\hline Transporte Pessoal & - & & 3.800 & 1.200 & & & & 5.000 \\
\hline Combustível & 1.500 & 1.500 & - & - & & & & 3.000 \\
\hline Outros custos & 1.850 & 1.500 & - & 800 & & & & 4.150 \\
\hline Total & 40.000 & 19.125 & 7.161 & 10.000 & - & - & - & $\begin{array}{r}76.28 \\
6\end{array}$ \\
\hline $\begin{array}{l}\text { Rateio } 1 \text { - } \\
\text { Administração }\end{array}$ & & 5 & 15 & 5 & - & - & - & - \\
\hline $\begin{array}{l}\text { B. de rateio }-n^{\circ} \text {. } \\
\text { func. }\end{array}$ & $\begin{array}{r}(40.000 \\
)\end{array}$ & 8.000 & 24.000 & 8.000 & - & - & - & - \\
\hline Total 1 & - & 27.125 & 31.161 & 18.000 & - & - & - & $\begin{array}{r}76.28 \\
6 \\
\end{array}$ \\
\hline $\begin{array}{l}\text { Rateio } 2 \text { - Man. } \\
\text { Central }\end{array}$ & - & & & & 52 & 52 & 52 & \\
\hline $\begin{array}{l}\text { B. de rateio - } \mathrm{h} \text {. } \\
\text { man. }\end{array}$ & - & $\begin{array}{r}(27.125 \\
)\end{array}$ & - & - & 9.042 & 9.042 & 9.042 & \\
\hline Total 2 & - & - & 31.161 & 18.000 & 9.042 & 9.042 & 9.042 & $\begin{array}{r}76.28 \\
6 \\
\end{array}$ \\
\hline $\begin{array}{l}\text { Rateio } 3 \text { - Custos do } \\
\text { Departamento }\end{array}$ & - & - & & & 1 & 1 & 1 & \\
\hline $\begin{array}{l}\text { B. de rateio - } \\
n^{\circ} \text {.equip. }\end{array}$ & - & - & $\begin{array}{r}(31.161 \\
)\end{array}$ & - & $\begin{array}{r}10.38 \\
7 \\
\end{array}$ & $\begin{array}{r}10.38 \\
7\end{array}$ & $\begin{array}{r}10.38 \\
7 \\
\end{array}$ & - \\
\hline Total 3 & - & - & - & 18.000 & $\begin{array}{r}19.42 \\
9 \\
\end{array}$ & $\begin{array}{r}19.42 \\
9 \\
\end{array}$ & $\begin{array}{r}19.42 \\
9\end{array}$ & $\begin{array}{r}76.28 \\
6 \\
\end{array}$ \\
\hline $\begin{array}{l}\text { Rateio } 4 \text { - Man. de } \\
\text { Campo }\end{array}$ & & - & - & & 78 & 78 & 78 & \\
\hline $\begin{array}{l}\text { B. de rateio - h. } \\
\text { man. }\end{array}$ & - & - & - & $\begin{array}{r}(18.000 \\
)\end{array}$ & 6.000 & 6.000 & 6.000 & - \\
\hline $\begin{array}{l}\text { Total custos } \\
\text { indiretos }\end{array}$ & - & - & - & - & 5.429 & $\begin{array}{c}25.42 \\
9\end{array}$ & $\begin{array}{c}25.42 \\
9\end{array}$ & $\begin{array}{r}76.28 \\
6 \\
\end{array}$ \\
\hline Total custos diretos & - & - & - & - & $\begin{array}{r}56.36 \\
0 \\
\end{array}$ & $\begin{array}{r}56.36 \\
0 \\
\end{array}$ & $\begin{array}{r}56.36 \\
0 \\
\end{array}$ & $\begin{array}{r}182.8 \\
75 \\
\end{array}$ \\
\hline CUSTO TOTAL & - & - & - & - & $\begin{array}{r}81.78 \\
9\end{array}$ & $\begin{array}{r}81.78 \\
9\end{array}$ & $\begin{array}{r}81.78 \\
9\end{array}$ & $\begin{array}{r}259.1 \\
61\end{array}$ \\
\hline Total horas trabalh. & - & - & - & - & 436,8 & 436,8 & 436,8 & $\begin{array}{r}1.310 \\
4\end{array}$ \\
\hline $\begin{array}{l}\text { CUSTO HORA MÁQ. } \\
\text { TRAB. }\end{array}$ & - & - & - & - & $\begin{array}{r}187,2 \\
5\end{array}$ & $\begin{array}{r}187,2 \\
5\end{array}$ & $\begin{array}{r}187,2 \\
5\end{array}$ & $\begin{array}{r}187,2 \\
5\end{array}$ \\
\hline
\end{tabular}


A partir dos novos custos apurados apresenta-se na Tabela 18 preço de venda que deve ser praticado pela empresa, caso ela opere em florestas com baixo volume e não esteja disposta a abrir mão da margem de lucro auferida quando opera em florestas que apresentam o volume/árvore ideal.

Tabela 18: Preço de venda - (margem de lucro desejada -

sem ineficiência da empresa)

\begin{tabular}{|l|c|c|c|r|}
\hline \multicolumn{1}{|c|}{ Descrição } & $\begin{array}{c}\text { Custo Total / } \\
\text { mês }\end{array}$ & $\begin{array}{c}\text { Produção / } \\
\text { mês }\end{array}$ & $\begin{array}{c}\text { Custo Unit. / } \\
\text { mês }\end{array}$ & Valor \\
\hline Custos variáveis & $117.381,00$ & $19.164,60$ & 6,12 & \\
\hline Custos Fixos & $127.985,00$ & $19.164,60$ & 6,68 & 12,80 \\
\hline Custo Total Unitário (\$) & & & & $22,99 \%$ \\
\hline Margem Lucro desejada & & & & 16,63 \\
\hline Preço de Venda Mínimo (\$) & & & & \\
\hline
\end{tabular}

Nota-se que o preço de venda apresenta uma variação de - 15,30\% quando comparado àquele calculado inicialmente $(\$ 19,62)$, o que significa que a ineficiência embutida pela empresa no custo do $\mathrm{m}^{3}$ de madeira cortada e descascada entregue ao cliente exerce uma influência significativa no custo final $e$, conseqüentemente, no preço do serviço prestado.

Deve-se observar que durante as negociações com a contratante, o gestor deve ser capaz de identificar e segregar os impactos das características da floresta, os quais não podem ser controlados por ele daqueles que estão sob seu controle (ineficiência da empresa), a fim de que os preços propostos sejam competitivos. Além disso, a análise da influência dos fatores controláveis pela empresa pode auxiliar os gestores na tomada de decisões relacionadas à troca de equipamentos e à investimentos no treinamento dos operadores de máquina, com o objetivo de melhorar sua lucratividade.

A Tabela 19 mostra o resultado operacional que seria obtido nas situações 1 e 2 (preço de venda de $\$ 15,00$ ), com todos os equipamentos operando nas condições de operação da Máquina 2. 
Tabela 19: Resultado operacional - (sem ineficiência da empresa)

\begin{tabular}{|c|c|c|}
\hline Descrição & Situação 1 & Situação 2 \\
\hline Horas trabalhadas & $1.310,40$ & $1.310,40$ \\
\hline Quantidade prod. $\left(\mathrm{m}^{3}\right)$ & $25.061,40$ & $19.164,60$ \\
\hline $\begin{array}{l}\text { Produção média por hora/trabalhada } \\
\left(\mathrm{m}^{3}\right)\end{array}$ & 19,13 & 14,63 \\
\hline Receita hora/trabalhada & 286,88 & 219,38 \\
\hline Receita Vendas & $375.921,00$ & $287.469,00$ \\
\hline (-) Custos variáveis & $(117.381,00)$ & $(117.381,00)$ \\
\hline Margem Contribuição & $258.540,00$ & $170.088,00$ \\
\hline Margem Contribuição \% & $68,78 \%$ & $59,17 \%$ \\
\hline (-) Custos Fixos & $(127.985,00)$ & $(127.985,00)$ \\
\hline Resultado Operacional Padrão & $130.555,00$ & $42.103,00$ \\
\hline (-) Custo Ineficiência & $(53.177,20)$ & $(43.910,80)$ \\
\hline Resultado Operacional Real & $77.377,80$ & $(1.807,80)$ \\
\hline Variação & $-40,73 \%$ & $-104,29 \%$ \\
\hline
\end{tabular}

A análise da Tabela 19 evidencia que a ineficiência da empresa, decorrente dos equipamentos velhos e da pouca habilidade dos operadores, causa expressiva redução no resultado operacional. Logo, como já mencionado, estes são fatores que merecem uma atenção especial dos gestores.

\section{ANÁLISE DO PONTO DE EQUILÍBRIO}

As seções que seguem têm como objetivo calcular e analisar o ponto de equilíbrio dos equipamentos e de cada uma das atividades. Consideram-se as seguintes situações possíveis:

Situação 1- a empresa presta serviços em uma floresta que apresenta as condições ideais de operação: considerando-se que o custo do $\mathrm{m}^{3}$ de madeira cortada e descascada varia de equipamento para equipamento, em função do custo hora/máquina e do volume produzido, o ponto de equilíbrio da atividade considera a margem de contribuição ponderada de cada um (Tabela 20).

Tabela 20: Margem de contribuição ponderada por máquina - (situação 1)

\begin{tabular}{|l|r|r|r|}
\multicolumn{1}{|c|}{ Descrição } & Máquina 1 & \multicolumn{1}{c|}{ Máquina 2 } & \multicolumn{1}{c|}{ Máquina 3 } \\
\hline Preço Venda Unitário $\left(\$ / \mathrm{m}^{3}\right)$ & 15,00 & 15,00 & 15,00 \\
\hline Custos Variáveis Unitária $\left(\$ / \mathrm{m}^{3}\right)$ & 4,68 & 4,68 & 5,20 \\
\hline Margem Contribuição Unitária $(\$)$ & 10,32 & 10,32 & 9,80 \\
\hline \% participação nas vendas & $29,26 \%$ & $37,23 \%$ & $33,51 \%$ \\
\hline Margem de Contribuição unitária & 3,02 & 3,84 & 3,28 \\
Ponderada (\$) & & & \\
\hline
\end{tabular}

Pela divisão dos custos e despesas fixas pela margem de contribuição ponderada obtém-se o Ponto de Equilíbrio da atividade, de 14.806,33 $\mathrm{m}^{3}$. Entretanto, como cada um dos equipamentos possui uma margem de contribuição diferente, é necessário desmembrar este ponto de equilíbrio, ou seja, qual é a produção que deve ser realizada por cada uma 
das máquinas. 0 ponto de equilíbrio de cada equipamento, em condições ideais de floresta (situação 1), é apresentado na Tabela 21 e o resultado operacional de equilíbrio, na Tabela 22.

Tabela 21: Ponto de equilíbrio contábil por máquina - (situação 1)

\begin{tabular}{|l|r|r|r|}
\multicolumn{1}{|c|}{ Descrição } & \multicolumn{1}{c|}{ Máquina 1 } & \multicolumn{1}{c|}{ Máquina 2 } & \multicolumn{1}{c|}{ Máquina 3 } \\
\hline Ponto de equilíbrio contábil da atividade $-\left(\mathrm{m}^{3}\right)$ & $14.806,33$ & $14.806,33$ & $14.806,33$ \\
\hline \% participação nas vendas & $29,26 \%$ & $37,23 \%$ & $33,51 \%$ \\
\hline Ponto equilíbrio contábil por máquina $\left(\mathrm{m}^{3}\right)$ & $4.331,64$ & $5.513,00$ & $4.961,70$ \\
\hline
\end{tabular}

Tabela 22: Resultado operacional no ponto de equilíbrio contábil por máquina - (situação 1)

\begin{tabular}{|c|c|c|c|c|}
\hline Descrição & Máquina 1 & Máquina 2 & Máquina 3 & Total \\
\hline$M^{3}$ - Ponto Equilíbrio & $4.331,64$ & $5.513,00$ & $4.961,70$ & $14.806,33$ \\
\hline Preço Venda Un. $\left(\mathrm{m}^{3}\right)$ & 15,00 & 15,00 & 15,00 & \\
\hline Custos Variáveis Un. $\left(\mathrm{m}^{3}\right)$ & 4,68 & 4,68 & 5,20 & \\
\hline Receita vendas & $64.974,60$ & $82.694,95$ & $74.425,45$ & $222.095,01$ \\
\hline (-) Custos variáveis & $(20.289,16)$ & $(25.821,42)$ & $(25.821,42)$ & $(71.932,01)$ \\
\hline Margem Contribuição & $44.685,45$ & $56.873,52$ & $48.604,03$ & $150.163,00$ \\
\hline Margem Contribuição \% & $68,77 \%$ & $68,78 \%$ & $65,31 \%$ & $67,61 \%$ \\
\hline (-) Custos Fixos & $(66.375,00)$ & $(41.894,00)$ & $(41.894,00)$ & $(150.163,00)$ \\
\hline Resultado Operacional & & & & - \\
\hline Margem operacional \% & - & - & - & - \\
\hline
\end{tabular}

Situação 2 - os serviços são prestados em uma floresta cujo volume/árvore é inferior ao considerado ideal, mas a empresa não consegue reajuste de preços: a Tabela 23 apresenta o cálculo da margem de contribuição ponderada, de cada uma das máquinas em tal circunstância (situação 2).

Tabela 23: Margem de contribuição ponderada e ponto de equilíbrio por máquina - (situação 2)

\begin{tabular}{|c|c|c|c|}
\hline Descrição & Máquina 1 & Máquina 2 & Máquina 3 \\
\hline Preço Venda Un. $\left(\$ / \mathrm{m}^{3}\right)$ & 15,00 & 15,00 & 15,00 \\
\hline Custos Variáveis Un. $\left(\$ / \mathrm{m}^{3}\right)$ & 6,13 & 6,12 & 6,81 \\
\hline Margem Contribuição Un. (\$) & 8,87 & 8,88 & 8,19 \\
\hline \% participação nas vendas & $29,26 \%$ & $37,23 \%$ & $33,51 \%$ \\
\hline Margem Contr. Un. Ponderada (\$) & 2,60 & 3,30 & 2,75 \\
\hline $\begin{array}{l}\text { Ponto de equilíbrio contábil da } \\
\text { atividade }\left(\mathrm{m}^{3}\right)\end{array}$ & $17.365,95$ & $17.365,95$ & $17.365,95$ \\
\hline \% participação nas vendas & $29,26 \%$ & $37,23 \%$ & $33,51 \%$ \\
\hline $\begin{array}{l}\text { Ponto equilíbrio contábil por } \\
\text { máquina }\left(\mathrm{m}^{3}\right)\end{array}$ & $5.080,46$ & $6.466,04$ & $5.819,44$ \\
\hline
\end{tabular}

Situação 3 - as condições da floresta não são ideais, mas a empresa obtém um reajuste de preço que garante a mesma margem de lucro obtida na situação 1 , repassando para a empresa contratante os custos relacionados à sua própria ineficiência: da mesma 
forma como calculado nas situações 1 e 2, a margem de contribuição ponderada, bem como o ponto de equilíbrio por equipamento é calculado (Tabela 24).

Tabela 24: Margem de contribuição ponderada e ponto de equilíbrio por máquina - (situação 3)

\begin{tabular}{|l|r|r|r|}
\hline \multicolumn{1}{|c|}{ Descrição } & Máquina 1 & \multicolumn{1}{c|}{ Máquina 2 } & \multicolumn{1}{c|}{ Máquina 3 } \\
\hline Preço Venda Un. $\left(\$ / \mathrm{m}^{3}\right)$ & 19,62 & 19,62 & 19,62 \\
\hline Custos Variáveis Un. $\left(\$ / \mathrm{m}^{3}\right)$ & 6,13 & 6,12 & 6,81 \\
\hline Margem Contribuição Un. $(\$)$ & 13,49 & 13,49 & 12,81 \\
\hline \% participação nas vendas & $29,26 \%$ & $37,23 \%$ & $33,51 \%$ \\
\hline Margem Contr. Un. Ponderada (\$) & $\mathbf{3 , 9 5}$ & $\mathbf{5 , 0 2}$ & $\mathbf{4 , 2 9}$ \\
\hline $\begin{array}{l}\text { Ponto de equilíbrio contábil da } \\
\text { atividade }\left(\mathrm{m}^{3}\right)\end{array}$ & $11.322,49$ & $11.322,49$ & $11.322,49$ \\
\hline \% participação nas vendas & $29,26 \%$ & $37,23 \%$ & $33,51 \%$ \\
\hline $\begin{array}{l}\text { Ponto equilíbrio contábil por } \\
\text { máquina }\left(\mathbf{m}^{3}\right)\end{array}$ & $\mathbf{3 . 3 1 2 , 4 3}$ & $\mathbf{4 . 2 1 5 , 8 2}$ & $\mathbf{3 . 7 9 4 , 2 4}$ \\
\hline
\end{tabular}

A análise do ponto de equilíbrio, nas três situações apresentadas, demonstra que embora as máquinas operem durante o mesmo número de horas seu ponto de equilíbrio é afetado pela mudança na produtividade, resultante da queda do volume das árvores cortadas e descascadas. A Tabela 25 apresenta um resumo dos diferentes pontos de equilíbrio das situações analisadas. Observa que na situação 2 , onde a empresa não obtém reajuste nos preços praticados, a quantidade de $\mathrm{m}^{3}$ de madeira necessárias para o ponto de equilíbrio no mês é significativamente maior.

Tabela 25: ponto de equilíbrio contábil

\begin{tabular}{|l|r|r|r|}
\hline \multicolumn{1}{|c|}{ Máquina } & \multicolumn{1}{c|}{ Situação1 } & \multicolumn{1}{c|}{ Situação 2 } & \multicolumn{1}{c|}{ Situação 3 } \\
\hline Máquina 1 & $4.331,64$ & $5.080,46$ & $3.312,43$ \\
\hline Máquina 2 & $5.513,00$ & $6.466,04$ & $4.215,82$ \\
\hline Máquina 3 & $4.961,70$ & $5.819,44$ & $3.794,24$ \\
\hline Total & $\mathbf{1 4 . 8 0 6 , 3 3}$ & $\mathbf{1 7 . 3 6 5 , 9 5}$ & $\mathbf{1 1 . 3 2 2 , 4 9}$ \\
\hline
\end{tabular}

É importante destacar que em todas as situações analisadas, o ponto de equilíbrio contábil é apurado com base nos custos reais incorridos durante o mês, o que significa que a ineficiência da própria empresa está inclusa no cálculo.

A Tabela 26 demonstra a quantidade de $\mathrm{m}^{3}$ de madeira que deveria ser cortada e descascada caso os efeitos negativos da baixa disponibilidade de uma das máquinas e da pouca habilidade de parte dos operadores fossem eliminados. Considera-se que a empresa opera em uma floresta com volume/árvore inferior ao volume ideal e o preço de venda reajustado não é calculado com base nos custos reais incorridos, uma vez que eles contemplam as ineficiências da empresa. Em outras palavras, nessa situação, a empresa cliente reajusta os preços apenas em função dos impactos das características da floresta, fator que não pode ser controlado pela contratada (situação 4). 
Tabela 26: Margem de contribuição ponderada e ponto de equilíbrio por máquina - (situação 4)

\begin{tabular}{|l|r|r|r|}
\multicolumn{1}{|c|}{ Descrição } & Máquina 1 & \multicolumn{1}{c|}{ Máquina 2 } & \multicolumn{1}{c|}{ Máquina 3 } \\
\hline Preço Venda Un. $\left(\$ / \mathrm{m}^{3}\right)$ & 16,63 & 16,63 & 16,63 \\
\hline Custos Variáveis Un. $\left(\$ / \mathrm{m}^{3}\right)$ & 6,12 & 6,12 & 6,12 \\
\hline Margem Contribuição Un. $(\$)$ & 10,50 & 10,50 & 10,50 \\
\hline \% participação nas vendas & $33,33 \%$ & $33,33 \%$ & $33,33 \%$ \\
\hline Margem Contr. Un. Ponderada (\$) & $\mathbf{3 , 5 0}$ & $\mathbf{3 , 5 0}$ & $\mathbf{3 , 5 0}$ \\
\hline $\begin{array}{l}\text { Ponto de equilíbrio contábil da } \\
\text { atividade }\left(\mathrm{m}^{3}\right)\end{array}$ & & & \\
\hline$\%$ participação nas vendas & $14.300,12$ & $14.300,12$ & $14.300,12$ \\
\hline Ponto equilíbrio $\left(\mathbf{m}^{3}\right)$ & $33,33 \%$ & $33,33 \%$ & $33,33 \%$ \\
\hline
\end{tabular}

Enfim, conforme demonstra a Tabela 26, mesmo operando em uma floresta com volume/árvore inferior ao ideal, a quantidade de $\mathrm{m}^{3}$ que deve ser produzida pela empresa para que ela atinja o ponto de equilíbrio diminui quando os impactos da sua própria ineficiência são eliminados.

Além do ponto de equilíbrio contábil em $\mathrm{m}^{3}$, com base na produção em $\mathrm{m}^{3}$ realizada por hora/máquina trabalhada é possível determinar quantas horas cada equipamento deve operar para que a empresa atinja o ponto de equilíbrio, conforme demonstrado na Tabela 27.

Tabela 27: Ponto de equilíbrio contábil em horas máq./trabalhadas

\begin{tabular}{|l|r|r|r|r|}
\multicolumn{1}{|c|}{ Máquina } & \multicolumn{1}{c|}{ Situação1 } & Situação 2 & \multicolumn{1}{c|}{ Situação 3 } & \multicolumn{1}{c|}{ Situação 5 } \\
\hline Máquina 1 & 226,49 & 347,38 & 226,49 & 325,93 \\
\hline Máquina 2 & 288,26 & 442,12 & 288,26 & 325,93 \\
\hline Máquina 3 & 288,26 & 442,12 & 288,26 & 325,93 \\
\hline Total & $\mathbf{8 0 3 , 0 1}$ & $\mathbf{1 . 2 3 1 , 6 3}$ & $\mathbf{8 0 3 , 0 1}$ & $\mathbf{9 7 7 , 7 9}$ \\
\hline
\end{tabular}

Vale observar que mesmo operando durante as horas calculadas na Tabela 27, caso a quantidade de $\mathrm{m}^{3}$ por hora/máquina produzida por cada um dos equipamentos não seja, no mínimo, igual à produção já determinada nas Tabelas 11 e 12 , o ponto de equilíbrio não é atingido pelo departamento, pois a empresa recebe de seu cliente por cada $\mathrm{m}^{3}$ de madeira cortada e descascada, e não pelas horas/máquina trabalhadas. Assim, o ponto de equilíbrio em horas/máquinas trabalhadas só é válido se a produção em $\mathrm{m}^{3} /$ hora prevista for alcançada. Outro aspecto que deve ser ressaltado é o fato de que, por meio do cálculo apresentado, até o momento obtém-se o ponto de equilíbrio contábil do departamento, ou seja, do conjunto de equipamentos que o compõem. Entretanto, destaca-se que este não é o ponto de equilíbrio do equipamento, quando analisado individualmente.

Tal fato pode ser constatado, por exemplo, por meio da análise do ponto de equilíbrio apresentado pela Máquina 1. Em qualquer uma das situações observadas é necessária a margem de contribuição das demais máquinas para cobrir os custos fixos da Máquina 1.

Para obter o ponto de equilíbrio do equipamento, deve-se levar em consideração a margem de contribuição gerada por ele, bem como seus custos e despesas fixas. Tomandose a situação 1 como exemplo, o cálculo do ponto de equilíbrio de cada equipamento é apresentado na Tabela 28. 
Tabela 28: Ponto de equilíbrio contábil de cada equipamento - (situação 1)

\begin{tabular}{|l|r|r|r|}
\multicolumn{1}{|c|}{ Descrição } & Máquina 1 & Máquina 2 & \multicolumn{1}{c|}{ Máquina 3 } \\
\hline Preço venda un. $\left(\mathrm{m}^{3}\right)$ & 15,00 & 15,00 & 15,00 \\
\hline Custos variáveis un. $\left(\mathrm{m}^{3}\right)$ & 4,68 & 4,68 & 5,20 \\
\hline Margem Contribuição un. $\left(\mathrm{m}^{3}\right)$ & 10,32 & 10,32 & 9,80 \\
\hline Custo e Despesas Fixas & $66.375,00$ & $41.894,00$ & $41.894,00$ \\
\hline Ponto equilíbrio contábil $\left(\mathrm{m}^{3}\right)$ & $6.434,14$ & $4.060,97$ & $4.276,71$ \\
\hline
\end{tabular}

A Tabela 29 apresenta a variação entre o ponto de equilíbrio de cada equipamento e o ponto de equilíbrio do conjunto de equipamentos.

Tabela 29: Ponto de equilíbrio de cada equipamento $X$ Ponto de equilíbrio do conjunto

\begin{tabular}{|l|r|r|r|l|}
\hline \multicolumn{1}{|c|}{ Descrição } & \multicolumn{1}{c|}{ Máquina 1 } & \multicolumn{1}{c|}{ Máquina 2 } & \multicolumn{1}{c|}{ Máquina 3 } & \multicolumn{1}{c|}{ Total } \\
\hline Análise do conjunto & $4.331,64$ & $5.513,00$ & $4.961,70$ & $14.806,33$ \\
\hline Análise individual & $6.434,14$ & $4.060,97$ & $4.276,71$ & $14.771,82$ \\
\hline Capacidade produtiva / mês & $6.563,70$ & $8.353,80$ & $7.518,42$ & $22.435,92$ \\
\hline
\end{tabular}

Nota-se, pelos dados da Tabela 29, que o ponto de equilíbrio de cada equipamento é diferente do ponto de equilíbrio do conjunto. Tal fato é relevante, pois, quando uma máquina, individualmente, não atinge o seu ponto de equilíbrio, necessita do resultado positivo gerado pelas demais.

Neste contexto, tanto a análise do ponto de equilíbrio do conjunto de máquinas, quanto de cada uma delas de forma segregada, é relevante para que o gestor possa compreender de que forma cada equipamento contribui para a formação do resultado apresentado pelo departamento.

\section{CONSIDERAÇÕES FINAIS}

O custo final do $\mathrm{m}^{3}$ de madeira cortada e descascada mecanicamente é influenciado por dois grupos de fatores distintos: aqueles considerados não controláveis, decorrentes das características da floresta onde o serviço é realizado, e aqueles controláveis, relacionados à gestão da empresa sobre os índices de consumo de seus equipamentos e disponibilidade operacional dos mesmos, bem como à qualificação técnica dos operadores contratados, ou seja, à sua eficiência ou ineficiência. Os impactos destes fatores controláveis e não controláveis, entende-se, devem ser analisados de maneira segregada, uma vez que estes últimos não podem ser repassados para o preço dos serviços oferecidos, sob pena de comprometer a competitividade da empresa.

Logo, a identificação e mensuração dos custos controláveis e não controláveis são essenciais para a análise e o desenvolvimento de meios para eliminar ou, pelo menos, reduzir os efeitos da ineficiência da empresa e dos impactos das peculiaridades da floresta no seu resultado.

Por esta razão, acredita-se que o presente trabalho contribui para que a empresa direcione ações visando atender às solicitações do contratante, operando nas florestas que ele determina, sem sacrificar a sua margem de lucro. Portanto, trata-se de um instrumento importante no gerenciamento da empresa, uma vez que oferece subsídios que podem 
auxiliar na gestão dos custos e na negociação dos preços de venda com o cliente, bem como no controle do volume das atividades realizadas.

\section{REFERÊNCIAS}

ASSOCIAÇÃO BRASILEIRA DE CELULOSE E PAPEL - BRACELPA. O Setor brasileiro de celulose e papel. Disponível em: http://www.bracelpa.org.br/br/anual/perfil2006.pdf . Acesso em: 23 abr. 2006a.

ASSOCIAÇÃO BRASILEIRA DE CELULOSE E PAPEL - BRACELPA. Relatório estatístico 2005/2005. São Paulo, 2006b.

CARVALHO, R. M. M. A.; SOARES, T. S.; VALVERDE, R. S. Caracterização do setor florestal: uma abordagem comparativa com outros setores da economia. Revista Ciência Florestal, Santa Maria, v. 15, 1, p. 105 - 118, 2005.

LEITE, Â. M. Pinto; SOUZA, A. P.; MACHAdO, C. C. Terceirização. In: MACHAdO, C. C. (Coord.). Colheita florestal. Viçosa: UFV, 2002, p. 423 - 444.

MACHADO, C. C. O Setor florestal brasileiro. In: MACHADO, C. C. (Coord.). Colheita florestal. Viçosa: UFV, 2002, p. 15 - 31.

MALINOVSKI, R.A.; MALINOVSKI, J. R. Evolução dos sistemas de colheita de pinus na região sul do Brasil. Curitiba: FUPEF, 1998.

MARION, J. C. Contabilidade rural: contabilidade agrícola, contabilidade da pecuária e imposto de renda - pessoa jurídica. 8. ed. São Paulo: Atlas, 2005.

MARTINS, E. Contabilidade de custos. 9. ed. São Paulo: Atlas, 2003.

PARISE, D. J. Influência dos requisitos pessoais especiais no desempenho de operadores de máquinas de colheita florestal de alta performance. Curitiba: UFP, 2005, $148 \mathrm{f}$. Dissertação (Mestrado em Engenharia Florestal), Faculdade de Ciências Agrárias, Universidade Federal do Paraná, 2005.

POLZL, W. B.; SANTOS, A. D. J.; TIMOFEICZYK, R.; POLZL, P. K. Cadeia produtiva do processamento mecânico da madeira: segmento da madeira serrada no estado do Paraná. Revista Floresta, v. 33, 2, 2003, p. 127 - 134.

ROESCH, S. M. A. Projetos de estágio do curso de administração: um guia para pesquisas, projetos, estágios e trabalho de conclusão de curso. São Paulo: Atlas, 2005.

SEIXAS, F. Extração. In: MACHADO, C. C. (Coord.). Colheita florestal. Viçosa: UFV, 2002, p $89-126$.

YIN, R. K. Estudo de caso. 3. ed. Porto Alegre: Bookman, 2005. 